\title{
La excavación arqueológica de las acequias de Mestalla y Petra junto al antiguo Molino de la Marquesa en la ciudad de Valencia
}

\author{
Víctor M. Algarra Pardo y Paloma Berrocal Ruiz \\ Gabinete de Arqueología Algarra y Berrocal \\ victorgabinetearqueologia@gmail.com, palomavicto@gmail.com
}

\begin{abstract}
Resumen. Entre los años 2007 y 2008 se practicó una excavación arqueológica en el solar del antiguo Molino de la Marquesa junto a la actual Av. de las Cortes Valencianas en la ciudad de Valencia, donde se documentaron amplios tramos de las acequias de Mestalla y de Petra. Fue posible reconstruir la secuencia estratigráfica completa desde su fundación, en torno al siglo XI, hasta la actualidad, así como la evolución del cauce en sus aproximadamente 1000 años de historia.
\end{abstract}

Palabras clave: Acequia, Molino, Arqueología, Secuencia Estratigráfica, Territorio Histórico.

Abstract. An archeological excavation was held between 2007 and 2008 in the old Marquesa's Mill besides the current Avenue of Cortes Valencianas in the city of Valencia, where vast sections of the Mestalla and Petra acequias were documented. These works made possible to rebuild the stratigraphic sequence from its origin, around the XI century, to the present day, as well as the evolution of the riverbed in its almost 1000 years of history.

Keywords: Ditch, Mill, Archaeology, Stratigraphic Sequence, Historical Territory.

\section{Introducción}

En las últimas décadas se han llevado a cabo diversas intervenciones arqueológicas en edificios rurales (alquerías y molinos) con motivo de su rehabilitación (o demolición) y en áreas sometidas a seguimientos de proyectos de obra pública o civil de fuerte impacto sobre el territorio del área metropolitana de Valencia, que han permitido la documentación de antiguos cajeros de acequias, así como otros elementos del paisaje agrario de la Huerta (caminos y parcelaciones).

El registro de las estructuras hidráulicas producto de estas excavaciones ha aportado una valiosa información acerca de su trazado, morfología y evolución, identificando las grandes fases constructivas de estos cauces milenarios y revelándose como una aportación imprescindible para comprender la configuración diacrónica de la red de acequias de la Huerta. Una de estas oportunidades excepcionales de excavación directa en las antiguas acequias la brindó la intervención practicada en el solar del antiguo Molino de la Marquesa y su entorno con motivo de las obras del Nuevo Estadio de Fútbol del Valencia C.F. entre los años 2007 y $2008^{1}$, donde circulaban y coincidían en un espacio próximo dos importantes

\footnotetext{
${ }^{1}$ La intervención se llevó a cabo entre agosto y noviembre de 2007 y fue financiada por la mercantil Valencia Club de Fútbol, S.A.D. y dirigida por los arqueólogos Paloma Berrocal y Víctor Algarra, formando parte del equipo de arqueólogos: Alejandro Vila, Dolores Ortega, Javier Máñez, Aquilino Gallego, Javier Pignatelli y
} 
acequias de la Vega de Valencia: la acequia de Mestalla y la de Petra, esta segunda uno de los principales brazos derivados de la anterior.

En concreto, de la Acequia de Mestalla se excavaron varios tramos tanto a la entrada como a la salida del Molino de la Marquesa, edificio en uso constante desde los siglos XIII-XIV hasta el XX, e incluso con evidencia material constatada de un origen musulmán. De la acequia se determinaron cinco grandes fases evolutivas, desde su fundación anterior al siglo XII hasta nuestros días. Del Braç de Petra también se documentó la secuencia completa de sus cajeros a lo largo del tiempo, situando el momento inicial de su trazado en una etapa postconquista cristiana entre los siglos XIII y XIV (Fig. 1).

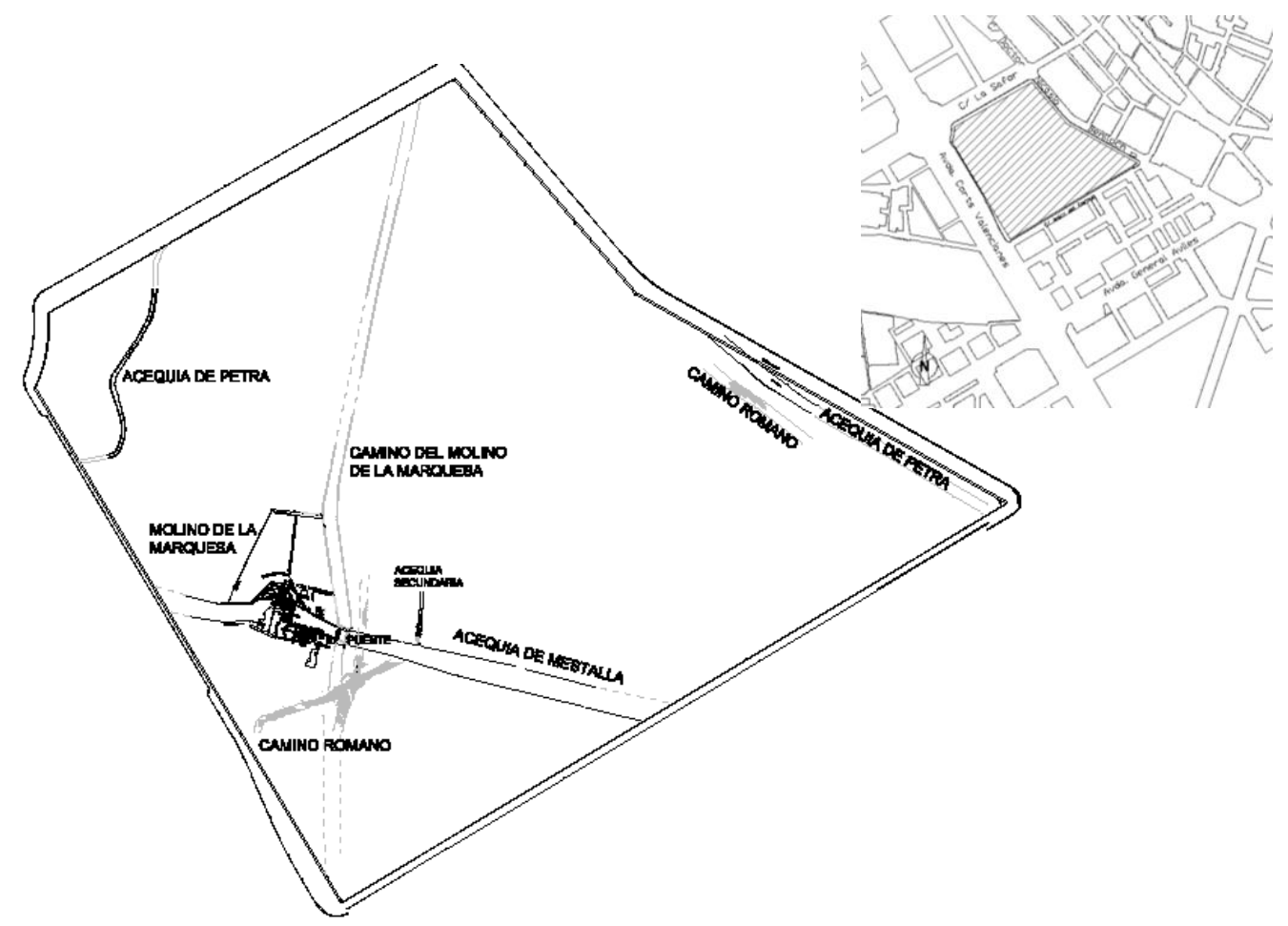

Fig. 1. Localización de la intervención del Molino de la Marquesa y los sectores sometidos a excavación en extensión

\section{Aproximación metodológica a la intervención en los cajeros}

A la hora de llevar a cabo una intervención arqueológica en los cajeros de una acequia se han de tener en cuenta una serie de consideraciones generales que influyen en la metodología, la detección de los cauces, la toma de datos y la interpretación misma de las evidencias halladas. El hecho de tratarse de un curso de agua que circula, habitualmente, por un

Ángela Herranz. La excavación y seguimiento se aplicó a los $84.2501 \mathrm{~m}^{2}$ del solar, si bien la excavación en extensión se centró en los $6.760 \mathrm{~m}^{2}$ del entorno del Molino de la Marquesa, donde se documentaron todas las estructuras de este casal con origen el s. XII y reedificado en el s. XIV, así como las instalaciones de la reconvertida fábrica de harina y posteriormente fábrica de papel. La excavación también se centró en la acequia de Mestalla, de la que se registró un total de 199 m (sometidos a excavación, seguimiento o zanjeado), en la acequia de Petra (analizada también en una segunda intervención entre abril y junio de 2008 junto a la c/ Nicasio Benlloch) y, finalmente, en otras estructuras como fueron el puente bajomedieval sobre la acequia de Mestalla, el camino del Molino de la Marquesa y tres caminos de época romana (150 m excavados en total). 
canal a cielo abierto, a excepción de tramos muy concretos (acequia en mina o alcavó, sifones, etc.), supone un contacto directo del cauce con la atmósfera, sin que medie estructura que lo aísle, sometida por tanto a reacciones físicas y químicas (evaporación, fusión, oxidación, decantación, contaminación, etc.).

A ello, y a diferencia de un río por el que siempre discurre el agua, se une la circunstancia particular para estas estructuras artificiales excavadas en la tierra de que el flujo de agua discurre de forma más o menos intermitente, en unos casos sólo cuando es el momento del turno de riego en los canales finales del sistema, que llevan el agua directamente a las parcelas de cultivo (files y regadores), y en otros cuando se corta el agua para realizar su limpieza y/o reparación (acequias madre, brazos y, en general, tramos pasantes de agua).

Esta alternancia en el paso del agua provoca que, entre un riego y otro, las superficies de las paredes y de la base mojadas entren en contacto con el oxígeno del aire el tiempo suficiente para que se produzca una reacción química de oxidación. Esta oxigenación se manifiesta en una coloración de un tono pardo-rojizo de las paredes y bases. Dicha circunstancia facilita el reconocimiento y la lectura de los cauces, sobre todo cuando llevamos a cabo una primera aproximación a su estudio mediante cortes.

Otra característica de este tipo de cursos es el de su pendiente, que condiciona una determinada dinámica de fluidos. Por lo general, en la Huerta de Valencia la pendiente es pequeña, obtenida tanto por las peculiaridades topográficas de este paisaje histórico, como por la propia conveniencia constructiva de estos canales. No obstante, podemos encontrarnos ante ciertos puntos o tramos donde el flujo puede ser turbulento, por alcanzar el agua una pendiente mayor, y por ello adquirir más velocidad, o al hallarse obstáculos en el curso, que provocan remolinos, que a su vez condicionan la sedimentación e incluso la integridad y forma del cajero (por ejemplo, grandes bloques tirados en la acequia que pueden provocar la excavación de fosas).

Sin embargo, la situación más habitual es la de flujos laminares, en los que el fluido presenta un movimiento ordenado, siguiendo láminas paralelas y estratificadas, al seguir una velocidad suave y, por lo general, constante. Consecuentemente, la posibilidad de transporte de sedimentos es reducida y aquellos que viajan en suspensión con el fluido o se arrastran por el fondo tienen la posibilidad de depositarse. Este motivo explica que el tamaño de los clastos que pueden observarse al interior de los cajeros es pequeño, por lo que hallaremos arcillas, limos, arenas y gravas inferiores a los $50 \mathrm{~mm}$, siendo poco frecuentes los cantos que superan los $60 \mathrm{~mm}$ (para que éstos puedan transportarse se requiere una pendiente igual a superior al 3\%, que no es habitual hallarla en estos canales).

Por último, y atendiendo no sólo a razones físicas, sino a motivaciones humanas e históricas, los cauces pueden haber variado su trayectoria y haber sido corregidos a lo largo del tiempo, no siendo estrictamente coincidentes con los que hayan llegado hasta nuestros días en funcionamiento o no, variando incluso la profundidad respecto al nivel de suelo actual, en algunos casos en varias metros de diferencia.

Por todo ello, y siempre que se tenga la posibilidad de excavar en un área amplia, disponiendo de suficientes metros longitudinales de acequia, conviene aplicar una metodología que pasa por dos fases de toma de datos, cada una de ellas válida para obtener un tipo de información concreta, tal y como pudimos llevar a cabo en esta intervención.

En la primera fase, tras localizar un punto de la acequia y teniendo como objetivo averiguar el trazado del canal en planta y en extensión, se deben realizar cortes transversales. Noso- 
tros realizamos catas de $2 \mathrm{~m}$ de anchura en el cajero mediante máquina excavadora distanciadas entre sí suficientemente. La lectura de los cortes resultantes es el mejor método para poder reconstruir la superposición de los cajeros a lo largo del tiempo, establecer su secuencia y determinar la dirección correcta del canal por el que discurría el agua. Se han registrado de este modo las grandes fases de transformación de su trazado. En este sentido, en la acequia de Mestalla se practicaron seis grandes zanjas, cuatro de ellas en un área alejada de la salida del molino de la Marquesa, para minimizar los condicionantes que este ingenio hubiera podido ejercer sobre el cajero.

En la segunda fase, sólo sabiendo a priori la morfología y cotas de cada cajero, se debe proceder a la excavación en extensión de los cauces, siguiendo la metodología propia de las relaciones estratigráficas y su individualización en unidades estratigráficas. De este modo, pudimos recuperar el suficiente material arqueológico para aproximarnos a los momentos constructivos de la acequia, conocer las composiciones de sus rellenos de anulación natural o artificial y la base geológica sobre la que se construyó (Fig. 2).
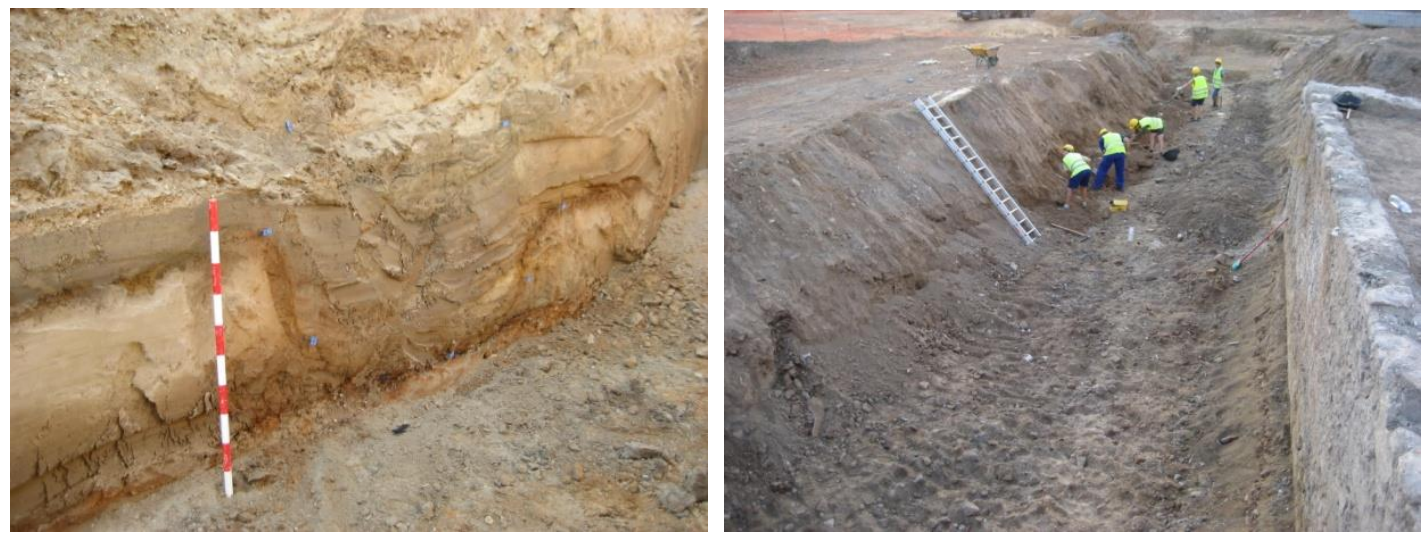

Fig. 2. Excavación arqueológica de la acequia de Mestalla. A la derecha estudio de cortes y a la izquierda excavación en extensión.

Llegados a este punto, las características de este tipo de estructuras, de nuevo, condicionan las posibilidades de datación de toda la secuencia. La sedimentación, por pequeña que ésta sea, es constante y junto a ella también lo es la deposición de materiales arqueológicos (arrastrados o depositados artificialmente por vertido directo). Sin embargo, periódicamente, la acequia experimenta una limpieza, previo vaciado del canal, para mantener la integridad del cajero y de la cota de riego. De este modo, se retiran los sedimentos acumulados e incluso es posible que se inviertan ciertos estratos sedimentados por la acción de limpieza y remoción del fondo.

Esta dinámica se mantiene mientras no exista una motivación especial por modificar a gran escala el curso, forma y sección del cauce, construyéndose uno nuevo a una cota superior. La datación de los cauces se complica ante estas circunstancias. Normalmente, se suele resolver por referencias estratigráficas, ya que la acción de cortar que efectúa la cubeta del cauce afecta a niveles anteriores que, de estar datados, pueden ayudar a situar una cronología aproximada para el inicio del nuevo canal. Respecto al periodo de uso, la imposibilidad de una precisión exacta en su adscripción cronológica viene dada por la misma acción de limpieza a la que nos acabamos de referir. $\mathrm{Al}$ efectuarse constantes limpiezas en el interior del cauce se eliminan la mayoría de las evidencias que hubieran existido. 
No obstante, en el momento de abandono, el cauce que va a ser corregido suele inundarse de sedimento, de manera que los restos de fragmentos de cerámicas y otros objetos que se quedan enterrados en el relleno de colmatación pueden ser recuperados, interpretados cronológicamente y, por ello, apuntarnos una datación a partir de la cual el canal preexistente ya no funciona. Igualmente, la relación estratigráfica del nivel que cubre a esta colmatación o de la estructura que la corta o invade de alguna manera nos conecta con un momento en el que el antiguo cauce ya no está en uso.

\section{Características de los cajeros y secuencia estratigráfica de las acequias de Mestalla y Petra}

\subsection{La Acequia de Mestalla}

Se han diferenciado un total de seis grandes fases en la acequia de Mestalla, que suponen transformaciones deliberadas y planificadas de su trazado (Fig. 3).

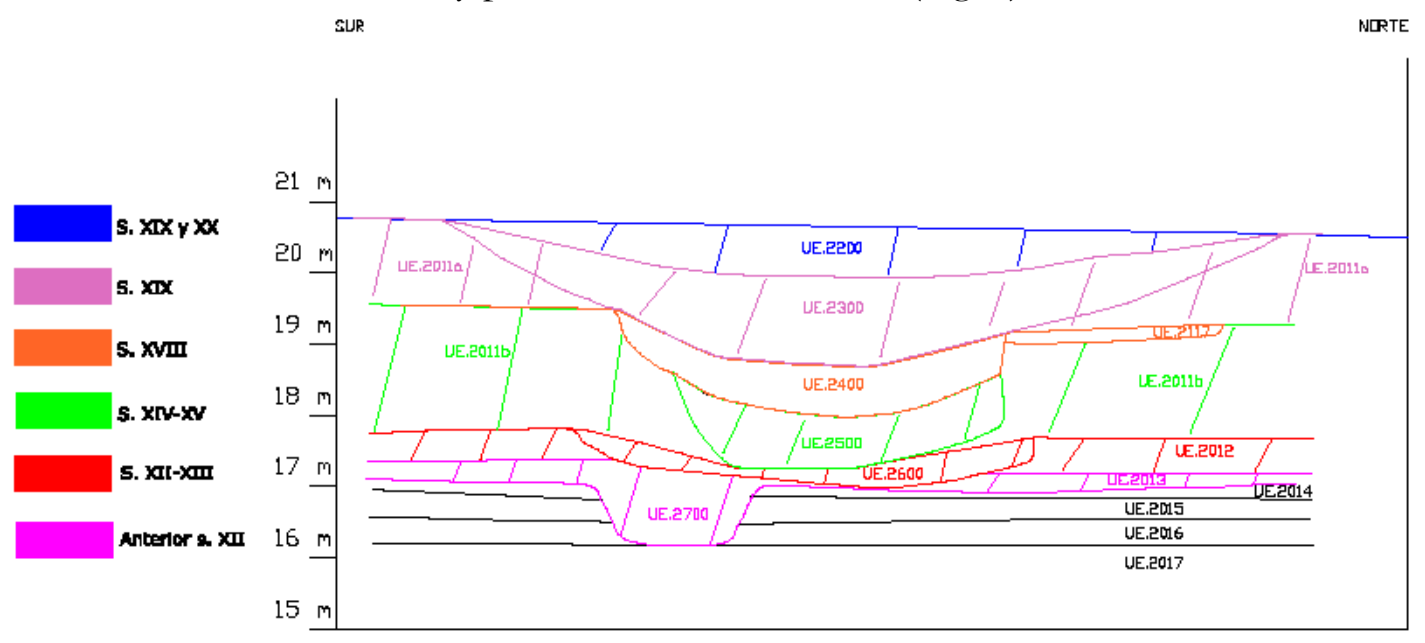

Fig. 3. Secuencia estratigráfica de la Acequia de Mestalla en un tramo alejado y al este del Molino de la Marquesa.

\subsubsection{Fase 1. Mestalla islámica, anterior al s. XII (UE. 2700).}

El primero y más antiguo de los cauces documentados durante nuestra intervención cortaba a una serie de niveles naturales de inundación anteriores a la existencia de la acequia, unos de arenas amarillas de grano variable y otros de arcillas marrones depositadas en láminas finas, que señalan los diferentes momentos de encharcamiento de la zona y posterior desecación, quedando cada uno de los niveles separados entre sí por una línea de oxidación que señala momentos de ausencia de agua y por tanto en contacto con el aire.

La base del cajero alcanzaba en ciertos puntos a un nivel aluvial compuesto por una mezcla de cantos rodados y gravas, con una matriz limo-arenosa de coloración amarillenta o rojiza, que se ha relacionado con el Barranc d'En Dolça, de cuyas implicaciones con la acequia hablaremos más adelante.

El canal presentaba una sección en cubeta de ángulos redondeados, con un ancho en la parte superior cuyas medidas oscilaban entre 1.65-1.86 m (con un máximo de $2.20 \mathrm{~m}$ en el 
extremo este del solar) y entre 1.20 y $1.50 \mathrm{~m}$ (reduciéndose a $1 \mathrm{~m}$ en algún punto) en la base. En ninguno de los casos el alzado conservado superaba el metro. Todo el canal poseía una fina capa limo-arcillosa que recubría el cajero y la base, evitando así la erosión de la arena en el que estaba excavado (Fig. 4).
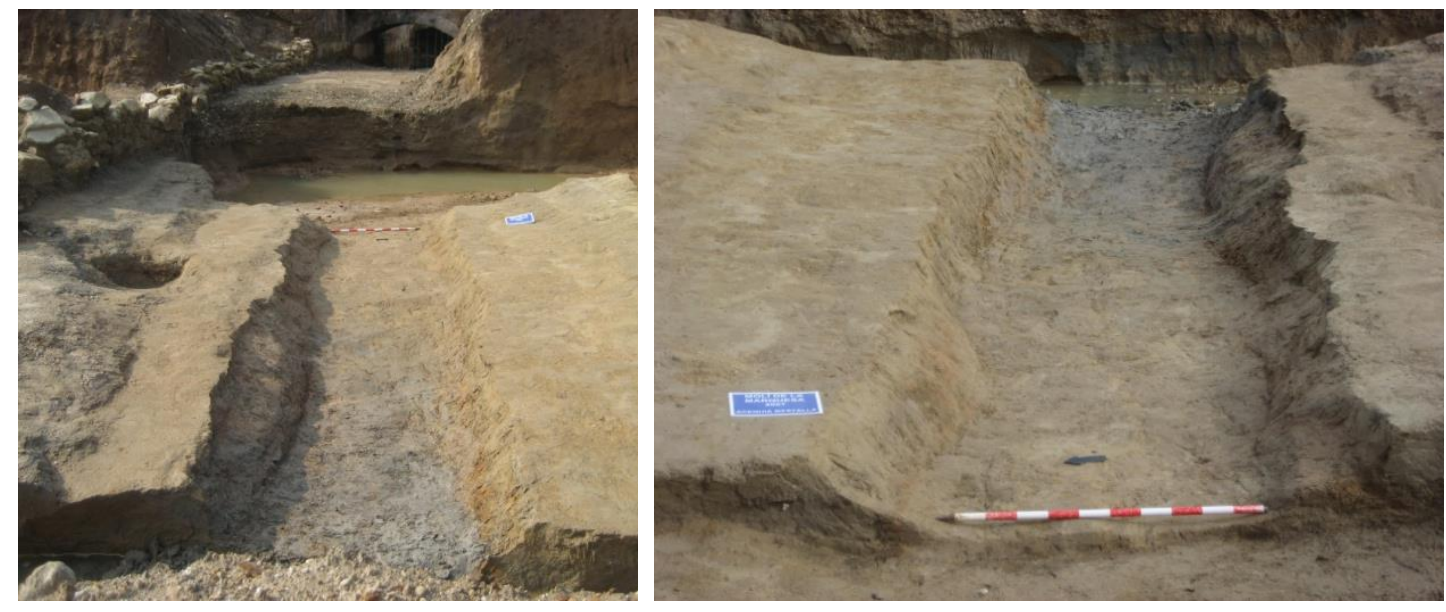

Fig. 4. Detalle de la acequia de Mestalla anterior al s. XII.

\subsubsection{Fase 2. Mestalla islámica, siglos XII-XIII (UE. 2600).}

En la etapa almohade se constata el funcionamiento de la segunda fase de la acequia de Mestalla, que supone importantes cambios estructurales y que marca el inicio de lo que a partir de entonces será el gran canal que, por su amplia dimensión, distribuirá agua a todo el sistema de Mestalla, integrado por las acequias de Petra, Rambla y Algiròs.

El cauce consistía en una amplia cubeta de paredes exvasadas y de base amplia, que oscilaba entre los $4 \mathrm{~m}$ de anchura en la parte superior de sus orillas, en el extremo noroeste anterior al molino de la Marquesa, y los 5.60 y hasta $6.50 \mathrm{~m}$ en el extremo este, alejado ya del molino. La base también se amplió entre 4.50 y $4.80 \mathrm{~m}$, mientras que la altura no aumentó en la misma proporción, manteniéndose una profundidad de unos $0.80 \mathrm{~m}$, similar a la de la primera fase (Fig. 5).

Este canal se mantuvo en uso hasta una etapa bastante avanzada de la época bajomedieval, al menos la segunda mitad del siglo XIV, aunque su cajero fue modificado puntualmente para adecuar las estructuras de conducción y distribución del agua a las cárcavas del molino de la Marquesa, construido en la transición de los siglos XIII y XIV, con muros de tapial calicostrado, que también se construyeron a la salida del molino en las dos orillas del cajero.

\subsubsection{Fase 3. Mestalla bajomedieval, siglos XIV-XV (UE. 2500).}

La tercera fase de la acequia ya es claramente de época bajomedieval y tiene una larga perduración a lo largo del siglo XV y la mayor parte de la época Moderna. Es la gran acequia que, durante esta larga etapa, conduce las dos terceras partes del caudal del agua de Mestalla hasta la derivación de las acequias de Rambla y Algiròs (el otro tercio corresponde a la acequia de Petra). Aunque su cajero se redujo ligeramente respecto al de la fase almohade, siguió conservando grandes dimensiones, de entre 4.40 y $5.50 \mathrm{~m}$ de anchura superior y entre $3.30 \mathrm{~m}$ y $4 \mathrm{~m}$ en la base. La profundidad, tomada en un punto alejado del molino, era ahora algo más grande, hasta $1.50 \mathrm{~m}$, de manera que la sección resultaba menos exvasada y más en cubeta (Fig. 6). 
La base de este canal estaba compuesta por un nivel compacto y consistente, de gravas, arenas y carbonatos de potencia desigual, en ocasiones detectable en todo el cajero y en otras sólo en los márgenes o en centro del canal. Los materiales recuperados en esta base nos permiten conocer el amplio margen de "vida" de este canal hasta aproximadamente la segunda mitad del siglo XVII o siglo XVIII.

Este largo periodo de uso supuso la construcción de estructuras que de un modo u otro afectaron a la acequia, pero que en definitiva no modificaron su diseño. En unos casos se trataba de muros de derivación del agua a las cárcavas del molino, de tajamares, de canales de aliviadero o de muros de contención del cajero de este ingenio tanto a la entrada como a la salida. En otros casos se trataba de elementos relacionados con las vías de comunicación, interrumpidas por este gran canal, como el puente existente para salvar la acequia en el Camino de la Marquesa, construido en el siglo XV. La bóveda del ojo del puente, que se ha logrado conservar, es de una rosca de ladrillo, con una luz de $5.55 \mathrm{~m}$, que descansa sobre dos potentes pilas de $5.25 \times 1.30 \times 1.30 \mathrm{~m}$, construidas en tapial calicostrado y en cuyo paramento exterior se aprecian las huellas del cañizo usado como empalizada para aislar la caja durante su construcción al interior de la acequia, así como las estacas de entibación (Fig. 7).

Finalmente, en el siglo XVII se construyeron muros para reforzar el viejo cajero de tierra, tanto en el tramo anterior del molino, con un muro de mampostería en seco, como pasado éste, de mampostería irregular, cantos rodados y fragmentos de muros de hormigón, fragmentos de ladrillos, trabados con mortero de arena y cal.

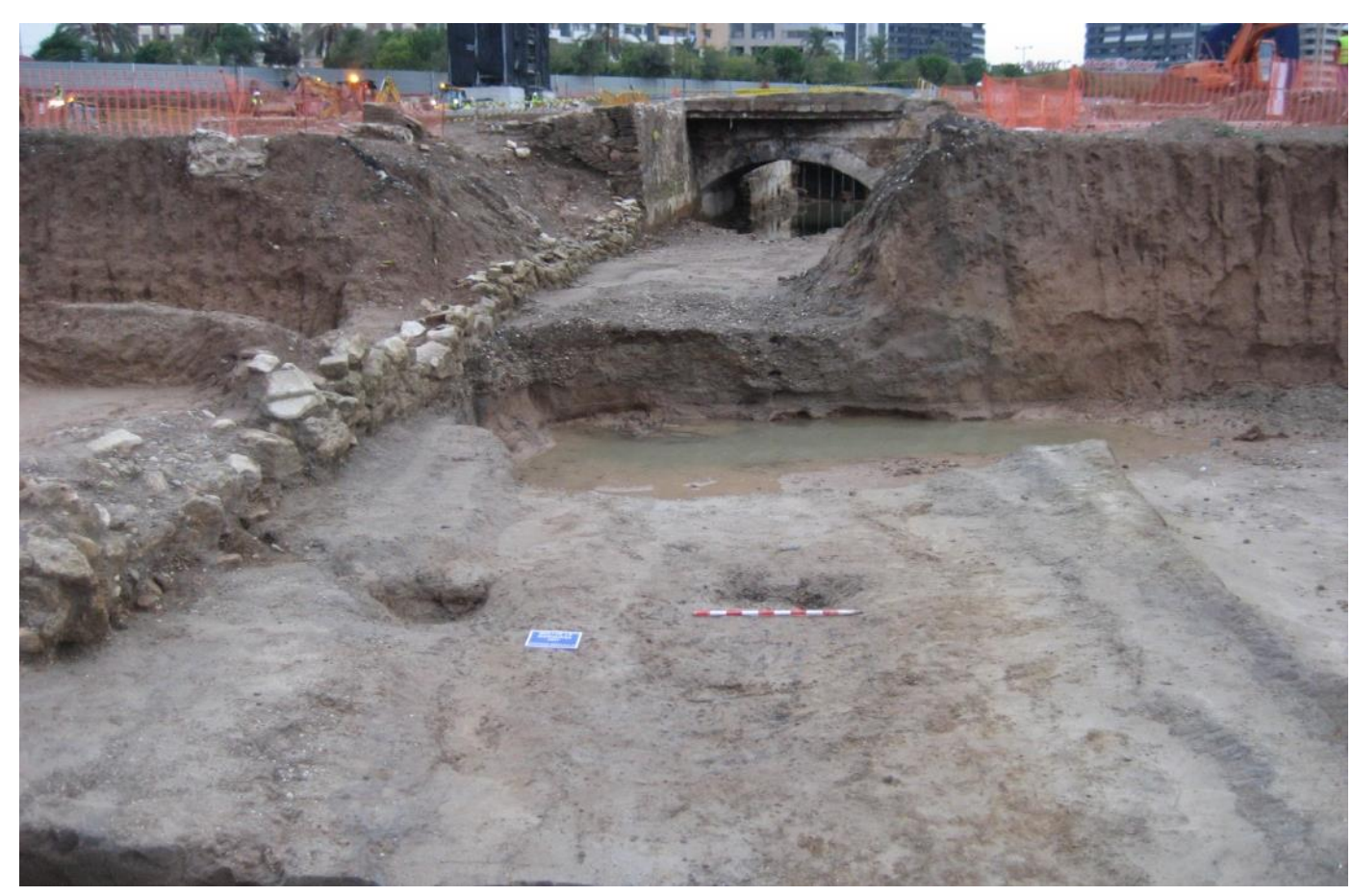

Fig. 5. Detalle de la acequia de Mestalla de época almohade. 


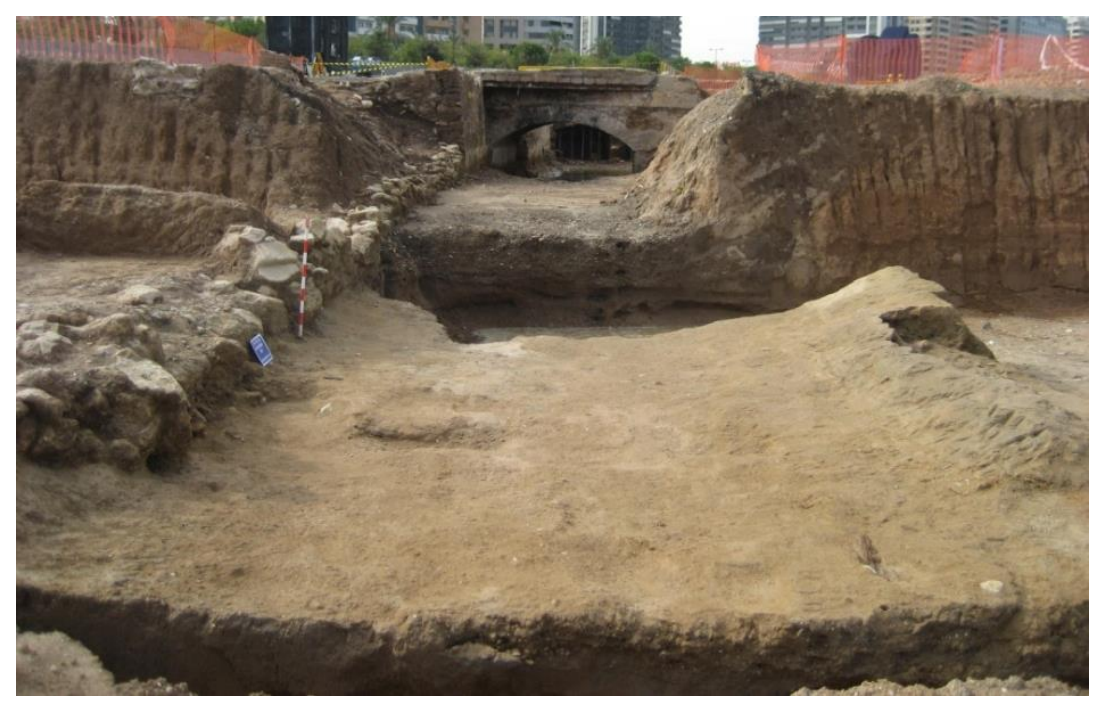

Fig. 6. Detalle de la acequia de Mestalla de época bajomedieval y moderna
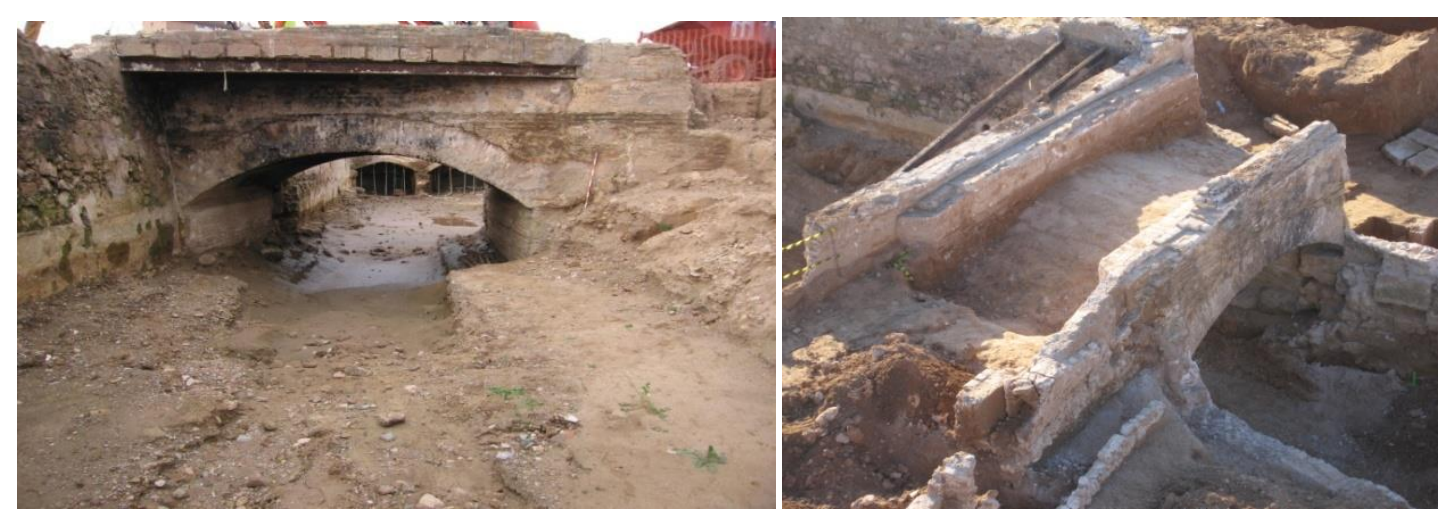

Fig. 7. Detalles del puente del s. XV sobre la acequia de Mestalla.

\subsubsection{Fase 4. Mestalla moderna, siglo XVIII (UE. 2400).}

La acequia de época bajomedieval-moderna recibió en su etapa final un relleno de sedimentación formado por capas de limos grises, alternadas con arenas de tamaño de grano heterogéneo, que finalmente fue cortado por la excavación de un nuevo cajero, de sección exvasada, con una anchura media de $5.50 \mathrm{~m}$ y una profundidad de $1.30 \mathrm{~m}$.

Su datación se estableció a partir de los materiales arqueológicos recuperados en el relleno de sedimentación, que indicaban un horizonte de finales del siglo XVIII (loza tipo à taches noires, loza azul, blanca y policroma).

\subsubsection{Fases 5 y 6. Mestalla contemporánea, siglos XIX y XX (UU. EE. 2300 y 2200).}

Es en la época Contemporánea cuando la acequia adquirió su máxima anchura, $8 \mathrm{~m}$ antes de pasar bajo el molino y entre 11 y $12 \mathrm{~m}$ alejada ya de éste, con una profundidad también considerable de casi $2 \mathrm{~m}$. Hasta su anulación, unos años antes de finalizar el siglo XX, ya no varió ni en su trazado ni en las dimensiones, pero sí recibió numerosos paquetes de sedimentos, formados por capas finas de arena $( \pm 2 \mathrm{~cm})$ con malacofauna, tanto terrestre como acuática, que evidencian un paso lento y reducido de agua en el amplio cajero. Además se vertieron o arrojaron al interior de la acequia elementos contaminantes y basura (sacos, neumáticos, suelas de zapato, hollín...) en buena parte procedentes de la fábrica de 
harina que desde finales del siglo XIX sustituyó al molino hidráulico y después fábrica de papel (década de 1920).

\subsection{La Acequia de Petra}

A partir de finales del s. XIII o principios del s. XIV, además de la acequia de Mestalla, discurrió por el área de la intervención arqueológica un nuevo cauce. Nos referimos a la acequia de Petra, la cual se documentó en dos puntos diferentes: un primer tramo en el apéndice oeste del solar, en la esquina formada por las actuales Avda. de Les Corts Valencianes y calle La Safor (87.83 m de longitud excavados), y un segundo tramo situado en el extremo opuesto, siguiendo la misma inclinación de la actual calle de Nicasio Benlloch $(59.51 \mathrm{~m}$ excavados), es decir en los dos extremos de la gran curva (o más bien ángulo) que forma esta acequia una vez pasado el cruce con la de Mestalla a la altura del desaparecido Molí de Sant Josep o d'Horta. Tomaremos como modelo para su descripción el tramo que va en paralelo a la c/Nicasio Benlloch, heredera en este punto del antiguo Camino Viejo de Llíria (Fig. 8).

\subsubsection{Fase 1. Petra en los siglos XIII-XIV.}

El cauce más antiguo detectado estaba formado por dos elementos: la propia acequia de Petra y una regadora o curso de agua más pequeño que discurría en paralelo y que se situaba junto a su margen derecho (oeste). Ya que el cajero más antiguo de la acequia original de Petra se encontraba más al este que el contemporáneo, sólo pudimos excavar unos 9.70 $\mathrm{m}$ lineales, siguiendo el resto del cauce antiguo por debajo de la acera actual.

Los dos elementos que formaban el tramo excavado aparecían a una considerable profundidad respecto al paso actual de las acequias. Según puede deducirse de los datos obtenidos de la excavación, y aunque este nivel estaba muy afectado por la acción de los cauces posteriores, la cota de suelo correspondiente a finales del siglo XIII y el XV se hallaba a 1.50 $\mathrm{m}$ por debajo del nivel actual de la calle.

El cauce de la acequia de Petra era un canal de una anchura media de entre 0.90 y $1 \mathrm{~m}$ y una altura máxima de $0.32 \mathrm{~m}$. De base bastante plana situada a una cota que iba desde una profundidad de -1.90 a $-2.10 \mathrm{~m}$ del nivel actual.

El canal que discurría a su derecha era bastante más pequeño que el de Petra. Se trataba de un cauce estrecho que se localizaba a una cota superior de $-1.50 \mathrm{~m}$ e inferior de $-1.90 \mathrm{~m}$. En el punto donde el cauce se encontró completo, éste se mostraba como una cubeta de sección en " u " excavada en la tierra, que llega a alcanzar una altura de $0.40 \mathrm{~m}$ y que tenía un ancho de $0.77 \mathrm{~m}$. Su pendiente discurría de norte a sur con una diferencia de cota no superior a $3 \mathrm{~cm}$ entre un extremo excavado y otro. (Fig. 9). Estuvo en funcionamiento durante todo el periodo bajomedieval, llegando con seguridad hasta el siglo XVI.

La cronología de estos dos cauces viene dada por los materiales cerámicos hallados en niveles asociados a ellos, como un fragmento de cuenco con decoración verde y manganeso de Paterna geométrico y fragmentos de piezas de cerámicas comunes vidriadas en monocromo y de cerámicas de cocina vidriadas correspondientes a los siglos XIII y XIV. 

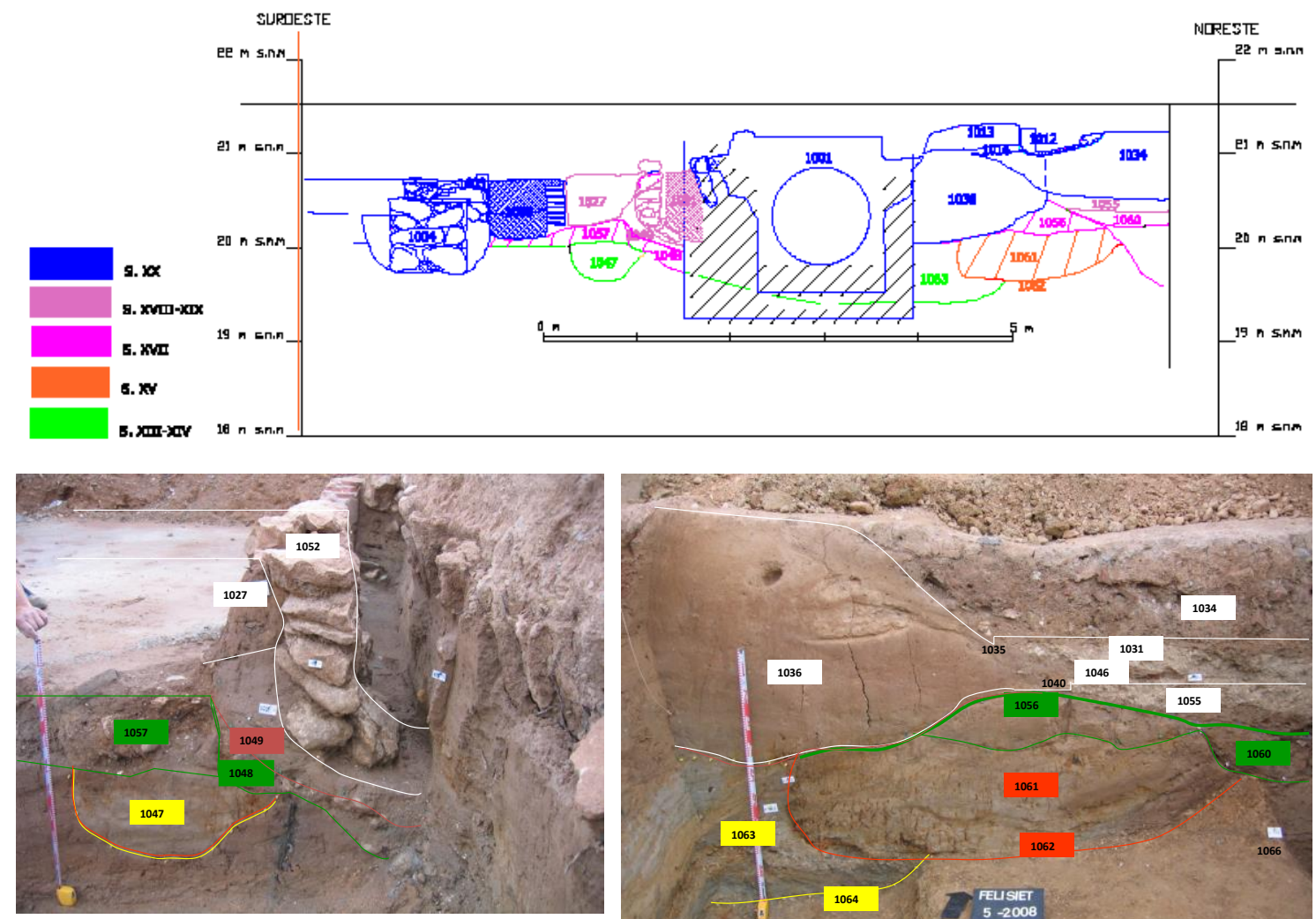

\section{S.XIV S.XV S.XVI-XVII S.XVIII-XIX S.XX}

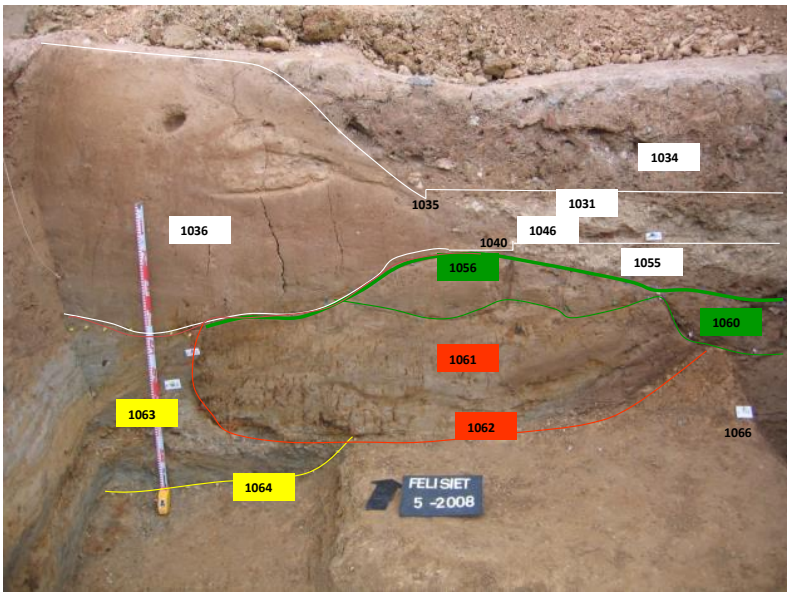

Fig. 8. Secuencia estratigráfica de la Acequia de Petra a la altura de la c/Nicasio Benlloch. Arriba sección, abajo cortes estratigráficos
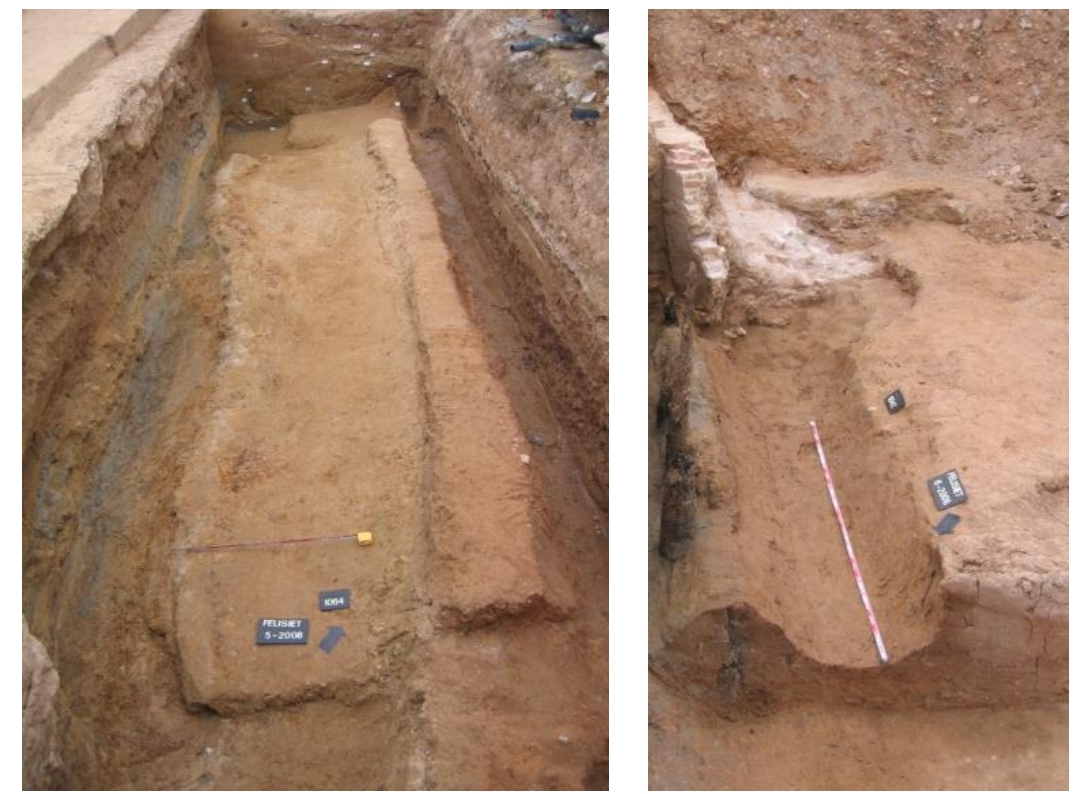

Fig. 9. A la izquierda cajero original de la Acequia de Petra. A la derecha regadora de Petra 


\subsubsection{Fase 2. Petra en el siglo XV}

Mientras que el roll o regadora que acabamos de presentar tuvo una vida bastante larga, el funcionamiento del cajero de la propia acequia de Petra experimentó un cambio significativo del mismo durante el siglo XV.

Este cambio se manifiestó en una corrección del cajero hacia el este, de manera que se excavó una nueva acequia a $3.33 \mathrm{~m}$ de distancia del roll, afectando de manera importante al cauce este de la antigua acequia e incluso al propio nivel natural.

Este nuevo cajero llegó completo hasta nosotros, habiéndose podido recuperar tanto su base como sus dos lados. Presentaba un cauce en sección abarquillada con un ancho de 1.50/1.60 $\mathrm{m}$ en la parte superior y aproximadamente 1.30/1.40 m en la inferior. Subió de cota respecto a la acequia anterior, situándose alrededor de unos $15 \mathrm{~cm}$ por encima de ella y aprovechó parte del relleno de colmatación del siglo XIV para excavar el lado oeste de su cauce. Por su parte, el lado este se excavó sobre el nivel natural, poniéndose en contacto con el único resto del camino Viejo de Llíria que hemos podido documentar en esta intervención. Este antiguo camino, que debía discurrir de forma paralela al barranco de Almara (calle Dr. Nicasio Benlloch), era una vía que se desarrollaba a una cota más baja que la propia acequia.

\subsubsection{Fase 3. Petra en el siglo XVII}

La anulación de la acequia medieval de Petra y de su roll o regadora se produjo tras la avenida de un paquete de arcillas que se situó por encima de ambas ocultándolas para siempre y ocasionando una corrección del cajero de Petra que se desplazó unos centímetros.

Esta avenida de arcillas de color marrón chocolate, tiene una potencia de entre $20 / 25 \mathrm{~cm}$ de espesor y, aunque se trata de un nivel muy depurado, han podido recuperarse algunos fragmentos cerámicos, en los que se mezclan piezas de los siglos XIV y XV con otras de época Moderna.

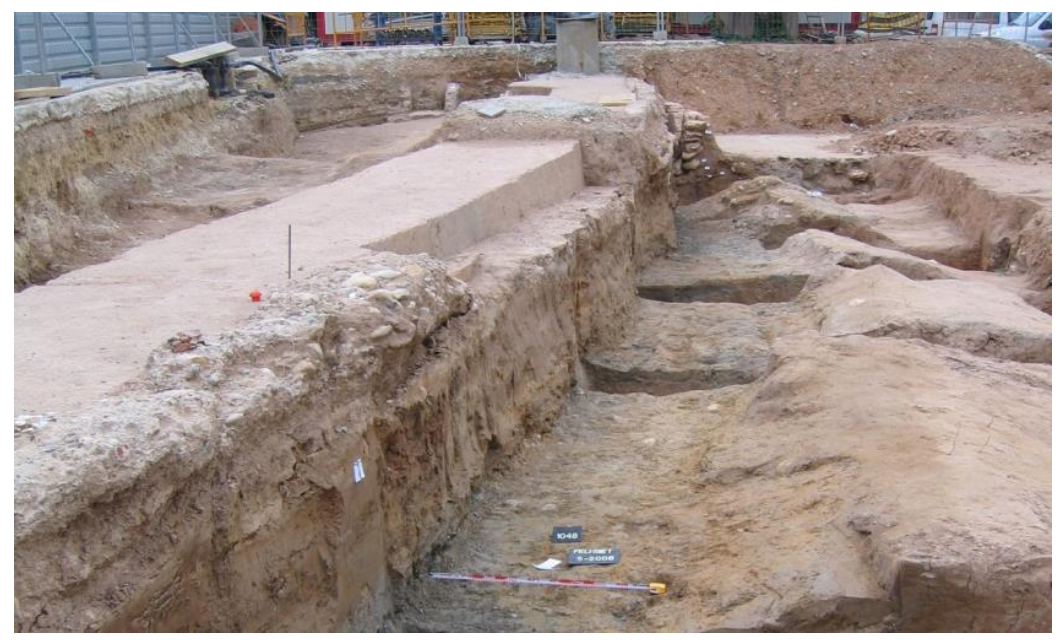

Fig. 10. Acequia de Petra de época Moderna, invadida por el actual colector.

En este nivel se excavó el cauce de Petra, que quedó cortado por la actual acequia entubada. La reconstrucción que se ha efectuado de este cauce nos remite a un canal de base ligeramente convexa y con un lado que sube en suave curva. Sobre estas superficies hay claros indicios de oxidación debido al paso del agua intermitente y su contacto con la atmosfera. Sumando los dos fragmentos de cauce a ambos lados de la acequia entubada actual, el dato más importante del canal de esta fase es su gran anchura respecto al de fases anteriores, alcanzando los $4.30 \mathrm{~m}$ y una profundidad de unos $40 \mathrm{~cm}$ (Fig. 10). 
Se ha calculado una perduración de esta acequia entre los siglos XVII y XVIII a partir de los materiales de los rellenos de sedimentación que van depositándose en la base del cajero: loza policroma con decoración zoomorfa del tipo "semilla de maíz", loza azul y loza dorada de Manises (s. XVII), junto a cerámicas comunes modernas vidriadas.

\subsubsection{Fase 4. Petra en los siglos XIX-XX}

A partir del siglo XIX y con toda seguridad durante el siglo XX se asienta el trazado definitivo de la acequia de Petra y de su roll. En las diversas subfases documentadas se mantiene, y aún supera, la anchura de la acequia moderna con anchos entre 4.65 y $4.50 \mathrm{~m}$. Siguen siendo cauces de tierra de sección ligeramente convexa con la base reforzada con un lecho de guijarros y, por primera vez, se registran refuerzos de las orillas mediante muretes de mampostería en ciertos puntos.

Su roll se situó a una distancia entre 0.75/1.00 m más hacia el oeste, llegando a discurrir de forma paralela con la fachada lateral de la alquería de Felisiet o del Barbut, que se construyó hacia principios del s. XX en este punto del Camino Viejo de Llíria.

\section{Estudio diacrónico de las acequias y el paisaje en el que se integran.}

Conocidas las fases y características de las acequias de Mestalla y Petra, pasamos a analizar las relaciones que guardan con los otros elementos del territorio histórico inmediato registrados, igualmente, en la intervención arqueológica. Esto nos permitirá obtener datos complementarios de la evolución del paisaje y, en concreto, de la conformación peculiar de los cajeros de las acequias a lo largo del tiempo (Fig. 11).

\subsection{La época romana, cuando la acequia todavía no existía}

La ocupación más antigua de este territorio se retrotrae al siglo I a.C, momento en el que transitan por él hasta tres caminos a una profundidad media de $5 \mathrm{~m}$ del nivel actual, que quedaron enterrados por sucesivas capas de sedimentación ya en periodo islámico. Los tres eran caminos formados por un lecho compacto de gravas de tamaño medio, entre las que se intercalaban guijarros de mayor tamaño. Sus contornos están claramente definidos mediante la disposición de estos guijarros y gracias a un peralte que los eleva en algunos puntos por uno de sus lados. Las gravas y guijarros no presentan una preparación diferenciada del firme, sino que el árido se asienta directamente sobre el mismo lecho arcilloso que conformaba el entorno encharcado del paisaje del siglo I a.C. Sus superficies muestran signos del incesante paso de carros, llegando a registrarse en los distintos tramos entre 2 y 4 carriladas o rodadas.

El camino que podemos considerar principal, por las civitates que supuestamente comunicaba: Valentia-Edeta, se localizó a unos $17 \mathrm{~m}$ de distancia de la actual calle Dr. Nicasio Benlloch, siguiendo una orientación noroeste-sureste y, en esencia, con semejante direccionalidad respecto a esta calle, la cual a su vez es la adaptación actual del histórico Camí de Llíria. El ancho máximo del camino con todos los elementos que lo componen es de $4.10 \mathrm{~m}$ (calzada, cuneta de evacuación y área rebajada y sin firme pero alisada en un lateral), mientras que estrictamente el firme con sus carriladas tiene una anchura de $2.80 \mathrm{~m}$ (Fig. 12). 
Esta vía debió verse afectada en varias ocasiones por distintas riadas o incluso desbordamientos de los barrancos ${ }^{2}$ situados en sus inmediaciones (barrancos d'En Dolça y de Almara). La potente capa de sedimentación (aproximadamente $1.25 \mathrm{~m}$ de potencia) más moderna corresponde a la época islámica, datada entre los siglos XII-XIII a partir de los escasos materiales recuperados, entre los que destacan 3 fragmentos de ataifores con vidriado verde oliva.

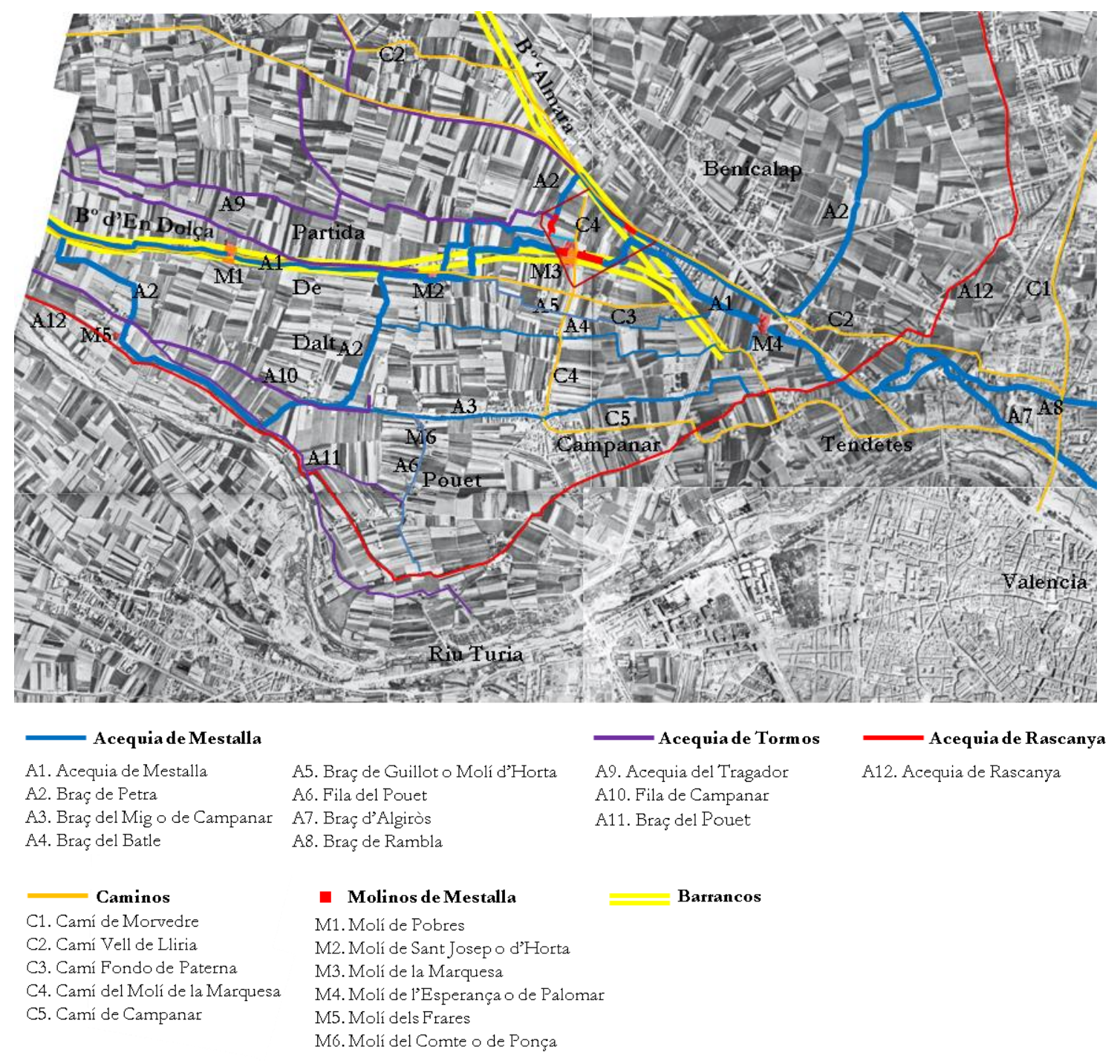

Fig. 11. Localización de los principales caminos, acequias, molinos y barrancos de parte del territorio histórico de Campanar y Benicalap, sobre el fotoplano de Valencia de 1944.

Este tramo, documentado a lo largo de $21 \mathrm{~m}$, hemos de interpretarlo como parte de la vía que unía la antigua Valentia y Edeta-Lauro (Llíria). Su heredero medieval, el Camí de Llíria, nacía a la altura del Camí de Morvedre y, bien siguiendo por el Pla de Saïdia (compartiendo vía con el camino que comunicaba la ciudad con Campanar) o atravesando Marxalenes, alcanzaba el área del Molí de l'Esperança, continuando después por el entorno de la actual calle Nicasio Benlloch.

\footnotetext{
2 Agradecemos la información y trazado de los barrancos suministrada amablemente por Carles Sanchis Ibor.
} 


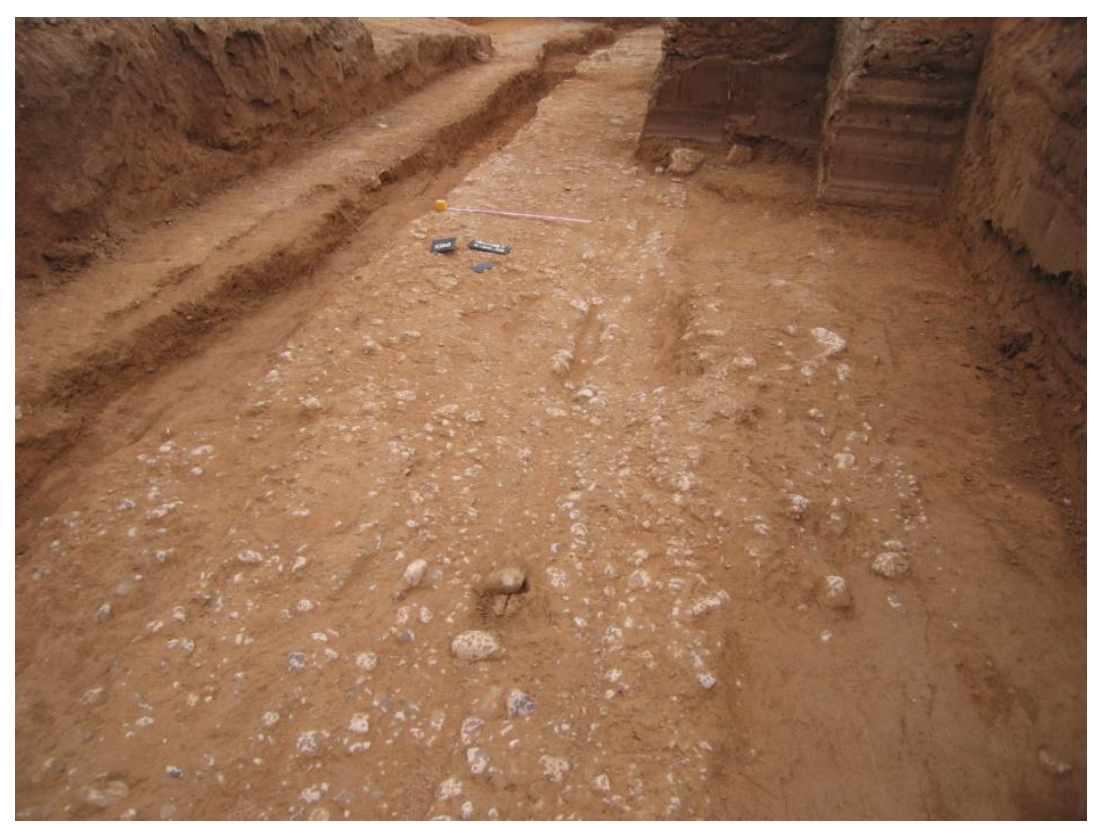

Fig. 12. Detalle del camino romano entre Valentia y Edeta, junto a la c/Nicasio Benlloch.

El segundo de los caminos partía del anterior y fue considerado como la fase más antigua y original del que muchos siglos después se conoció como Camí del Molí de la Marquesa, que desde más de 2.000 años ha enlazado el Camí de Llíria con el núcleo de Campanar. En efecto, separado unos metros del eje del camino medieval del Molino de la Marquesa, seguía una dirección ligeramente noroeste-sudoeste, oscilando su anchura entre los 3.30 y los $3.80 \mathrm{~m}$. En su recorrido quedaba cortado por el cauce actual de la acequia de Mestalla y debía vadear el barranco d'En Dolça en un punto donde este accidente presentaba una cota algo más baja, como más adelante veremos.

Salvado este curso natural, y en un punto casi inmediato a él, se cruzaba con el tercero de los caminos, cuya intersección pudo ser bien documentada. Este tercer camino de 2.90-3 m de anchura seguía una orientación este-oeste y también se halló cortado por el cauce más moderno de la acequia de Mestalla, pero a diferencia del anterior posiblemente no vadeaba el barranco (al menos no en este punto), sino que pudo acompañarlo en su recorrido, eso sí, a una cota mucho más alta en su margen derecha. No se hallaron niveles de caminos más modernos sobre él, sin embargo, nos parece indudable que se trata de un tramo posteriormente desechado del Camí Fondo de Paterna, que a la altura de Tendetes se desgajaba del Camí de Campanar, debiendo acompañar, en origen, a la curva final del Barranc d'En Dolça (pasando por ello por la zona de intervención arqueológica en el entorno del Molí de la Marquesa) hasta el desaparecido Molí d’Horta y, a partir de aquí, siguiendo el trazado del barranco, que coincide con el de la posterior acequia de Mestalla. Sobre el camino se documentó una potente capa de sedimento arcilloso de cronología islámica, que lo anuló, de manera que a partir de ese momento debió llevar una trayectoria más al sur, tal y como ha llegado hasta nuestros días (Fig. 13).

Por todo lo visto, el entorno del Molí de la Marquesa fue desde antaño un punto estratégico en cuanto a las vías de comunicación que lo atravesaban. Y en cuanto a los barrancos, ¿cómo se relacionaron estos caminos y los barrancos de Almara y En Dolça? El camino de Valentia-Edeta apareció a una cota de 18.82 m.s.n.m. (-5.18 m del nivel actual) y en el área excavada hasta el límite mismo de la calle Nicasio Benlloch no se halló evidencia alguna del 
Barranc d'Almara, que supuestamente discurría en este punto en paralelo al camino. Por ello suponemos que la primitiva vía se situaba en la margen derecha del barranco y separada unos metros de este paleocauce a una cota, como es evidente, más elevada. A escasos metros del camino y también en la supuesta margen derecha 13-14 siglos después se construirá la Acequia de Petra, aprovechando la misma cota más elevada respecto al barranco.

Hacia el sur, hasta el Barranc d'En Dolça, el terreno subía ligeramente hasta la cota 19.53 m.s.n.m. en la que se encontraba el segundo de los caminos, unos centímetros más elevado que el primitivo camino que se encaminaba a Paterna (cota 19.20 m.s.n.m., $-4.80 \mathrm{~m}$ del nivel actual). Pero el dato de mayor interés que se desprende de estas cotas es la diferencia de más de $2.50 \mathrm{~m}$ respecto a la base del primero de los cajeros (fase 1 anterior al siglo XII) de la acequia de Mestalla, el cual a la altura del cruce de los caminos se situaba a la cota sensiblemente más profunda de 16.97 m.s.n.m. Es este el indicador más seguro para concluir que ya desde época romana los niveles de suelo transitado se encontraban al menos más de $2.50 \mathrm{~m}$ por encima del cauce del barranco.

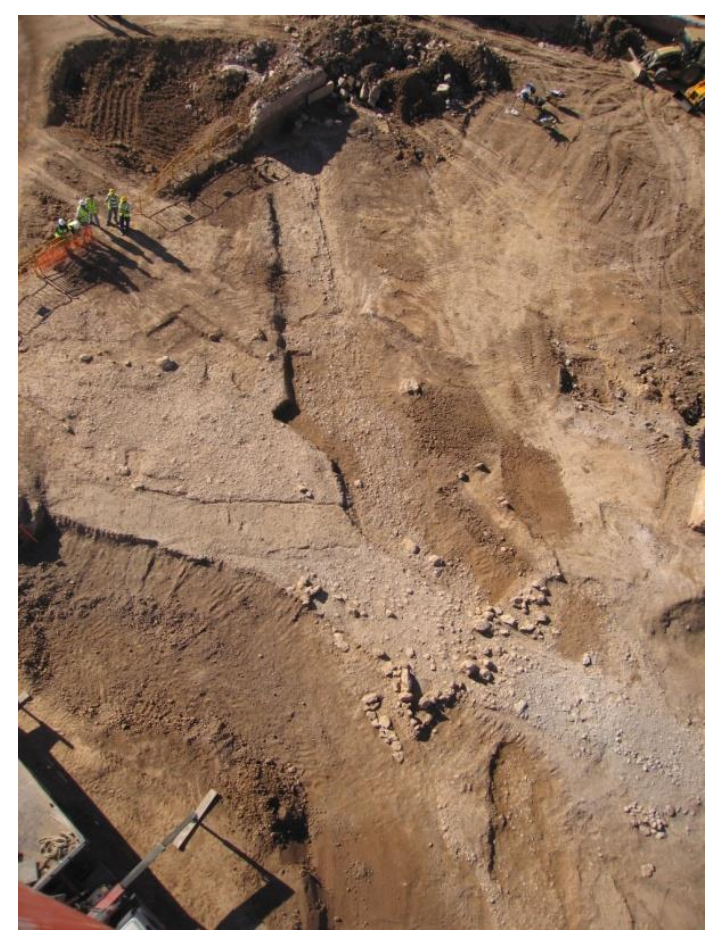

Fig. 13. Vista aérea del cruce de caminos romanos.

\subsection{De la construcción de la primitiva acequia de Mestalla hasta el final de la época islámica}

\subsubsection{Fase 1. El entorno y la acequia de Mestalla anterior al periodo almohade}

Hemos datado la construcción del primero de los cajeros de la Acequia de Mestalla en una etapa anterior al siglo XII. Como señalamos al comienzo de este trabajo, este tipo de estructuras de carácter "negativo" (excavadas y con escasas o nulas estructuras construidas que se le asocien) no suelen conservar niveles relacionados con el momento de la construcción, como sí ocurre con un edificio (zanjas de cimentación, nivelaciones de obra y de colocación de pavimentos, etc.), lo que dificulta su datación por la ausencia casi absoluta de materiales coetáneos a su fundación. A ello se une la constante limpieza de los cajeros, lo 
que impide una estratificación completa y continuada en el tiempo de los sedimentos que se depositan. Por ello, la datación de una fase viene marcada, por lo general, por una cronología post quem, derivada de fenómenos sedimentarios cercanos en el tiempo a la siguiente fase de la acequia, es decir se puede considerar que el sedimento que se documenta sobre un cajero corresponde a la capa que ya no se retiró previa a la acción a gran escala (no de limpieza) de remodelación de un sistema hidráulico o, al menos, de un tramo extenso (no de pequeñas y puntuales reparaciones).

Estas grandes actuaciones constructivas en las acequias no se efectúan a la ligera y en periodos cortos de tiempo (lo que colapsaría y pararía la producción agraria), sino que vienen motivadas por importantes cambios en las necesidades del reparto del agua o por concepciones radicalmente distintas del poder y de la organización social de cada etapa, sin descartar otras posibles causas naturales como avenidas y riadas.

En nuestro caso, sobre el cajero primitivo ya en funcionamiento se depositó un relleno formado por numerosas capas de árido limo-arenoso de coloración verde y negro y, además, en ambos márgenes se hallaron depositados pequeños paquetes de arenas amarillas de grano fino. Los materiales arqueológicos recuperados se limitan a un fragmento de galbo de olla raspada datado entre los siglos XI y XII y tres fragmentos de cerámicas bizcochadas de cronología ibero-romana. La cronología de estos materiales y la superposición de la segunda fase todavía islámica de la acequia nos inclinan a datar el cauce original antes del periodo almohade de la segunda mitad del siglo XII y aventurar una datación en el siglo XI o algo anterior.

Hemos visto que la primitiva acequia presentaba un cajero modesto, si se compara con el de su segunda fase todavía datado en la época islámica. La anchura máxima de los márgenes superiores oscilaba entre 1.70 y $2.20 \mathrm{~m}$, dependiendo de tramos, y la inferior o de base entre $1.40-1.50 \mathrm{~m}$ (reduciéndose a $1 \mathrm{~m}$ en algún punto). Son medidas relativamente pequeñas si las comparamos con la amplitud de cauce que va a experimentar esta misma acequia unos años después, aún en periodo islámico (Fase 2).

En cuanto a las cotas de la base del cauce, tomamos referencias en tres puntos distanciados suficientemente entre sí para comprobar cuál era su pendiente. Desde el extremo noroeste al sudeste las cotas son de 18.65 m.s.n.m. (-5.35 m del nivel actual), 16.60 m.s.n.m. en el punto central y 16.25 m.s.n.m. en el extremo opuesto (-7.75 $\mathrm{m}$ del nivel actual).

El desnivel de la base del cajero entre los dos puntos más extremos es de $2.40 \mathrm{~m}$ en una distancia de $152 \mathrm{~m}$, es decir una pendiente del $1.57 \%$. La pendiente es todavía más pronunciada en el extremo noroeste y la central con una diferencia de cota de $2.05 \mathrm{~m}$ en $85 \mathrm{~m}$ de distancia, por lo que la pendiente es del $2.39 \%$. Finalmente, entre el punto central y el extremo sudeste, separadas por $67 \mathrm{~m}$, la diferencia de cota es de tan sólo $0.35 \mathrm{~m}$, de manera que la pendiente se reduce al $0.52 \%$. Estos datos nos presentan un curso de agua bastante más abrupto en el extremo noroeste de la zona excavada, que en el centro y extremo noreste, donde el cauce debía discurrir de forma más suave.

Esta diferencia entre cotas tan acusada en muy pocos metros es cosa poco habitual en este tipo de estructuras hidráulicas, donde la pendiente de un cauce es ligera y constante. Una posible explicación que lanzamos como hipótesis puede ser la de que la acequia se adapte al Barranc d'En Dolça, como han puesto de manifiesto algunos autores que han estudiado 
esta acequia (E. Guinot y S. Selma ${ }^{3}$ ). El paso de una cota de 18.65 m.s.n.m. a 16.60 m.s.n.m. indica claramente un desnivel natural bastante pronunciado en este punto del cauce, hecho que será aprovechado en el siglo XII para la construcción de un molino hidráulico, precedente del molino de la Marquesa, que se benefició del impulso que podía ofrecer este desnivel.

\subsubsection{Fase 2. El entorno y la acequia de Mestalla del periodo almohade}

A partir de la segunda mitad del siglo XII situamos el momento de reformas generalizadas del cajero de Mestalla, que tiene como característica principal la conversión de la acequia en un cauce de gran amplitud y que coincide en un mismo horizonte temporal con la construcción del primitivo molino islámico, antecedente del Molino de la Marquesa.

Este nuevo cajero se mantuvo en uso hasta el siglo XIV (¿segunda mitad?), cuando se registra una nueva e importante sedimentación sobre la acequia que no se retira. La acequia en esta segunda fase se transforma radicalmente, pasando a convertirse en una gran acequia "madre" de $4 \mathrm{~m}$ de anchura en el extremo noroeste y entre 5.60 y $6.50 \mathrm{~m}$ al otro extremo del cauce.

¿Cuál pudo ser la motivación de esta transformación? Enric Guinot y Sergi Selma (2005, p.46) sugirieron una interesante hipótesis sobre el origen de Mestalla basada en los peculiares perímetros de riego y, en general, en la morfología de los tres brazos principales de Mestalla: Petra, Rambla y Algiròs y, asimismo, en la organización misma de la acequia, con sequiatge y sequier propio para cada uno de estos tres brazos hasta nuestros días. Estos autores opinan que la acequia de Mestalla, tal y como la conocemos a partir de época bajomedieval, es el resultado de la fusión de estos tres brazos principales (acequias independientes en su origen), que disponían de azudes propios.

Creemos que esta fusión se produce en esta segunda fase y que conlleva un aumento de caudal de agua que puede ponerse en relación directa con el ensanchamiento tan evidente que experimenta el cauce de Mestalla en nuestra excavación.

En resumen, si recordamos la acequia original de Mestalla documentada en esta intervención, y que pudo funcionar desde al menos el siglo XI al XII, vemos que por sus reducidas dimensiones no pudo satisfacer la demanda de agua suficiente de una supuesta "acequia madre" que abasteciese el riego de todos sus perímetros históricos (Petra, Rambla y Algiròs). Más bien la primitiva acequia parece adaptarse a un perímetro menor, el del área de la alquería islámica de Campanar y el comprendido entre las alquerías de Olleria y Marxalenes (braç de Goleró), que se corresponden con los actuales primeros perímetros de riego de Mestalla.

Esta argumentación, que en modo alguno puede elevarse a la categoría de teoría confirmada, daría sentido a la aparentemente caótica distribución de los perímetros de riego de Mestalla (exceptuando a los de Rambla y Algiròs, los cuales, considerados autónomos, tienen una lógica de sucesión en el área del margen izquierdo del Turia, entre el Camí de Morvedre al oeste, el mar al este, Benimaclet al norte y el río-Grau al sur).

Sin embargo, la segunda fase documentada de nuestra acequia, con las nuevas dimensiones que ya conocemos, sí podría considerarse una verdadera "acequia madre", aptada a la or-

\footnotetext{
3 Para conocer un extenso y fundamentado análisis del trazado de la acequia de Mestalla, de sus brazos, perímetros de riego y de los elementos hidráulicos que la conforman véase, Mangue (2001) y Guinot y Selma (2005).
} 
ganización de Mestalla que nos es familiar, es decir capaz de hacer frente a todas las particiones que sufre en sus brazos de Petra, Rambla y Algiròs. Por ello coincidimos con E. Guinot y S. Selma en la existencia de un cambio organizativo de la acequia, materializado en una fusión de antiguas acequias independientes, que creemos pudo no producirse a raíz de la implantación de la nueva sociedad feudal, sino ya antes en el periodo final de la etapa islámica entre los siglos XII y XIII.

En cuanto a la segunda de las novedades para esta fase 2, hemos podido documentar la construcción de un molino almohade sobre la acequia de Mestalla, justo en aquel punto donde veíamos el mayor desnivel del cauce. Estas primeras estructuras corresponden a lo que posteriormente se conocerá como el molino de la Marquesa. No creemos que su construcción sea una causa del cambio del cajero, pero sin duda la reforma de éste favoreció todavía más si cabe la edificación de una instalación molinera, valiéndose de este salto de agua.

Los restos arquitectónicos registrados en la intervención arqueológica se sitúan en el margen sur de la acequia, en el espacio de comunicación de los dos cuerpos principales del molino bajomedieval (el casal del molino harinero y el del molino draper), allí donde fue menor la fuerte intrusión del molino datado en el siglo XIV. Los restos son escasos, apenas dos muros en esquina de tapial calicostrado y los restos de unos escalones de una posible balsa. Asimismo se registraron diversas fosas, una incluso bajo los dos muros del molino islámico. El relleno de estas fosas aportó materiales de una cronología de esta última etapa islámica: lebrillos, jarritas, cántaros y medidor de grano, ollas bizcochadas, ollas meladas y grises y vajilla vidriada en verde, melado, turquesa, blanco y bícroma con ataifores en manganeso sobre melado y en blanco y verde.

Junto a estos elementos arqueológicos descritos, se documentó la existencia de una fase de camino de este mismo momento almohade, heredero del precedente camino romano del Camí del Molí de la Marquesa. Presentaba un firme similar al del primitivo del s. I a.C. y se situaba a una cota también próxima a él (19.56 m.s.n.m.), es decir cerca de $3 \mathrm{~m}$ por encima de la base de la acequia, y que como el romano cruzaba o vadeaba un curso de agua, ahora una acequia, allí donde la pendiente se suavizaba y se regularizaba a la salida del molino.

\subsection{Las acequias de Mestalla y Petra en la época bajomedieval}

La consolidación de la sociedad feudal sobre el territorio valenciano se manifestó, como no podía ser de otro modo, también en las estructuras hidráulicas, viarias y arquitectónicas que hemos ido describiendo, aunque en el caso de la acequia de Mestalla no asistiremos a una modificación estructural de su cauce hasta un momento bien avanzado de la época bajomedieval, de manera que la gran acequia del periodo final islámico se mantuvo en uso durante bastante más de un siglo después de la conquista cristiana de Valencia.

Los grandes cambios en el área, inmediatos a la implantación de la sociedad feudal entre las décadas finales del siglo XIII y principios del XIV, serán la construcción de un grandísimo complejo molinero asentado sobre el viejo casal islámico y sobre todo, el paso a unas pocas decenas de metros de un brazo nacido de la propia acequia de Mestalla aguas abajo: la Acequia de Petra (Fig. 14). 


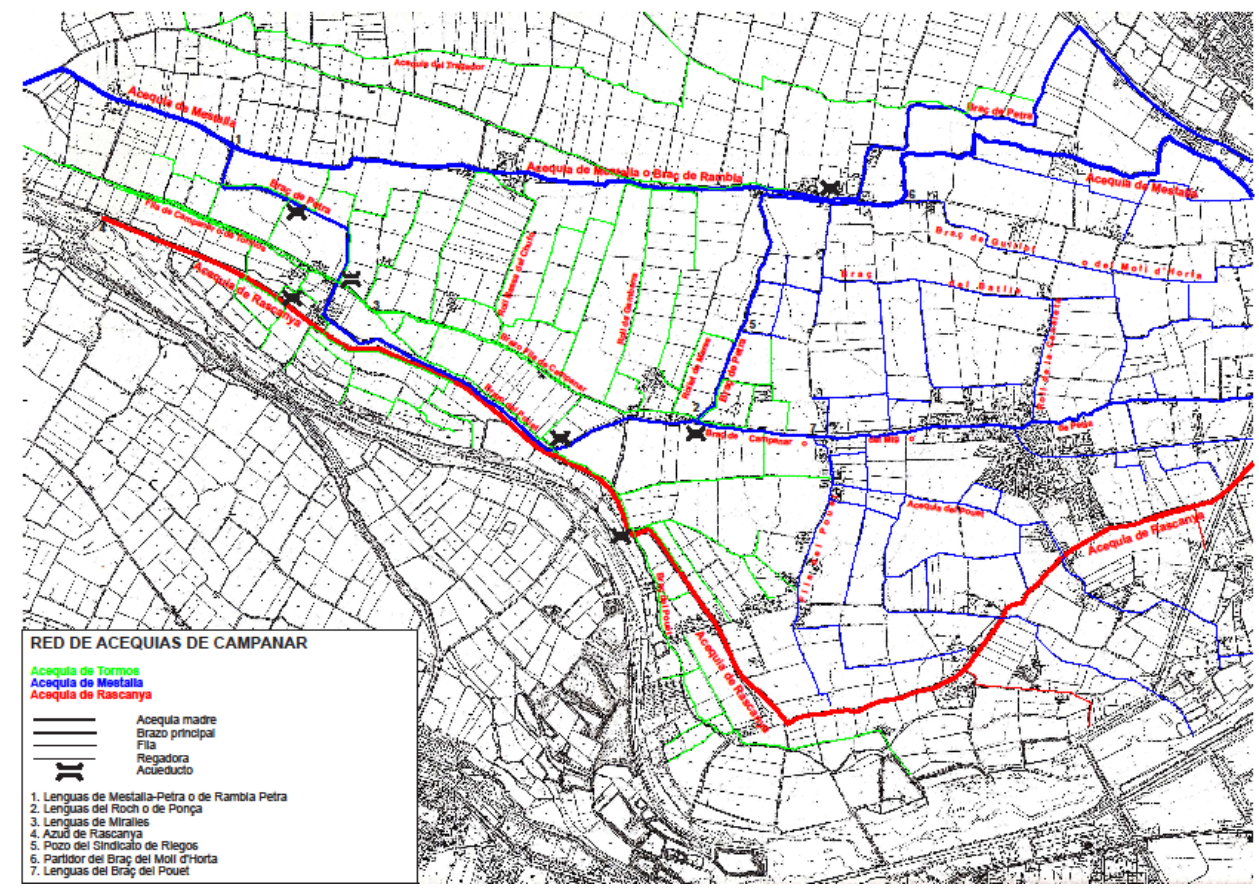

Fig. 14. Localización en el parcelario de 1929 de las acequias de Mestalla, Tormos y Rascanya

\subsubsection{El Molino de la Marquesa y la Acequia de Mestalla}

Hacia finales del siglo XIII o principios del siglo XIV hemos centrado el momento de construcción del molino que, con el tiempo, se conoció como Molino de la Marquesa. El edificio se construyó como un gran conjunto molinero que iba a acoger actividades diversas, todas ellas aprovechando la fuerza hidráulica de la Acequia de Mestalla.

A partir de la documentación archivística ${ }^{4}$ exhumada durante los trabajos de campo arqueológicos en el año 2007 pudimos conocer la propiedad del molino a principios del siglo $\mathrm{XV}$ e incluso acceder a un inventario de bienes para estas mismas fechas. En 1419 Joan de Claramunt (prohombre de la ciudad de Valencia, Justicia Civil entre 1403 y 1404 y jurado de 1418 a 1419) como dueño de un molino comparece junto a Francesc Palomar (procurador de su madre $\mathrm{Na}$ Ramoneta), también dueño de un molino (el molí de l'Esperança o de Palomar), ante la Cort de la Governació del Regne de València por un pleito de denuncia ${ }^{5}$ de la realización de una "almenara ab caxes e cuberta tota, que és amagada, per la cual almenara discorren totes del aygües [pluviales como se repite a lo largo del documento] que venen en lo dit cami de Paterna e donen en la Céquia de Miztalla on són construbits los molin del dit Joan de Claramunt e na Ramoneta la qual almenra o discorriment de les diyes aygües del dit camí, jamés no fon en los dits camí ne céquia, et la qual almenara, per los dessús dits, és stada closa, per lo gran dan que per aquella rebien en los dits llurs molins". Esta almenara fue cegada por los demandantes ("closa e tanquada ab argamas$\left.s a^{\prime}\right)$ y se especifica que el agua pluvial que venía por el Camí de Paterna pasaba por la almenara y caía en la acequia pudiendo dañar a los molinos con la fuerza de aguas estacionales y torrenciales. Se aportan datos suficientes para confirmar que el molino de Joan Claramunt es el Molí de la Marquesa, por ser el molino ubicado inmediatamente aguas arriba de Mestalla del Molí de l'Esperança o Palomar, por situarse junto al Camí de Paterna y por el "pont qui és en lo dit camí, per lo qual dit cami passen al moli del honrat en Johan Claramunt",

\footnotetext{
4 Agradecemos a Luis Pablo Martínez Sanmartín la información y la ayuda prestada para ponernos en la pista de las series documentales en las que era posible hallar documentación de este molino. El estudio documental del Molino de la Marquesa fue realizado por Aureli Silvestre Romero.

5 Arxiu del Regne de València, Governació, Litium, 2.221, mà 6a , f. 38 r y v.
} 
puente que pudo registrarse arqueológicamente y recuperarse en su total integridad. Además de la constatación de la propiedad del molino, para el tema que nos ocupa son interesantes los detalles de este pleito en relación a una almenara o escorredor ilegal que conduciría las aguas a la acequia, acción esta perjudicial para los dueños de los molinos, pero que evidencia el paso estacional de agua por el Camí de Paterna, como vía natural de desagüe en paralelo y como alternativa al curso natural del Barranc d'En Dolça, ya convertido en acequia.

En 1421 se efectuó un inventario del molí de Joan Claramunt ${ }^{6}$ que estaba compuesto por "uns casals de molins fariner en lo qual cinch moles arreades e uns casals de drapers o pilaters on havia dues maces arreades; e uns casals de moli arrocer on havia sis maces arreades de nou, tots contigus, franchs e quitis, situats en la cèquia de Miz̧talla, ab un troç de terra campa, la qual és denant e attinent dels dits casals de molins". El registro arqueológico ha permitido documentar al menos dos de estas actividades, la de molinería de harina y la de batán de paños, en lo que se conocía como "molí draper". Se han documentado dos grandes conjuntos, uno de ellos implantado sobre la acequia de Mestalla, que acogía la actividad de molino harinero, y tal vez también de arroz, y un segundo conjunto al sur de la acequia, perteneciente al "molí draper" (Fig. 15).

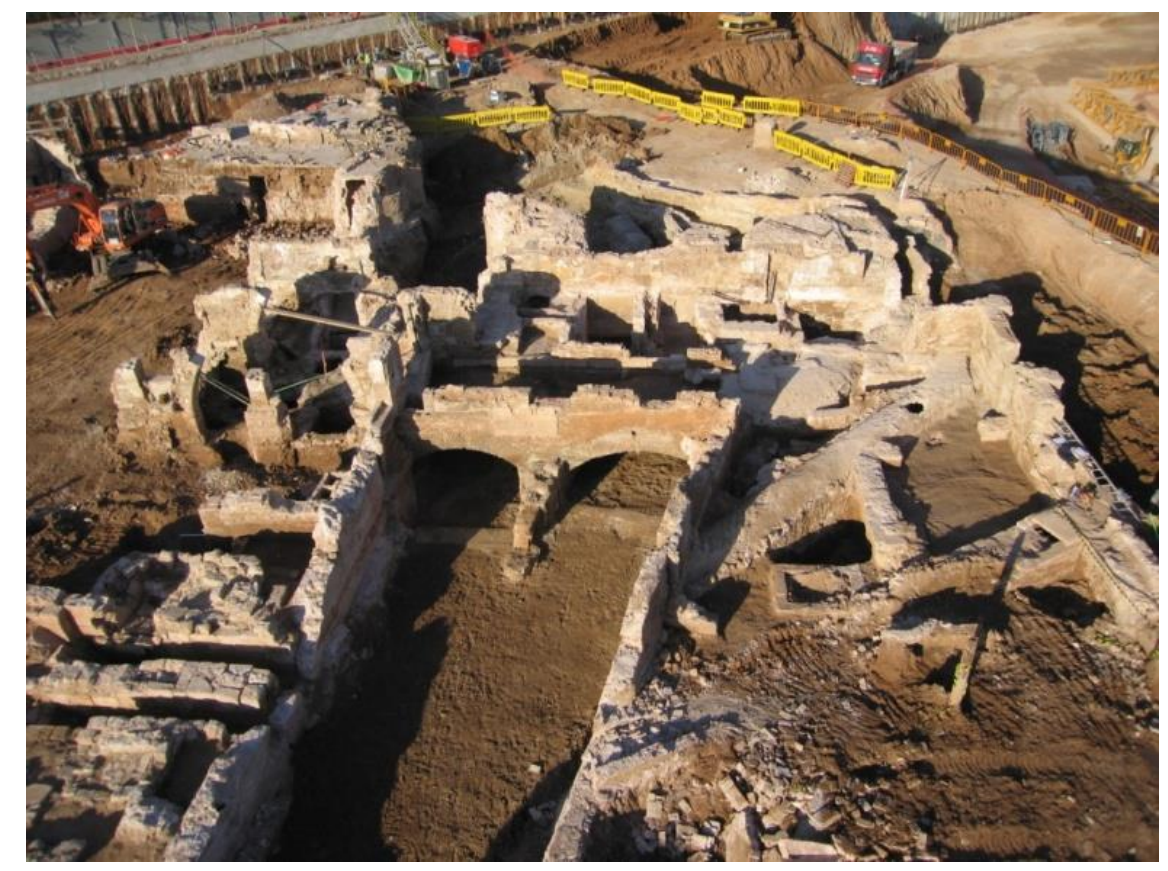

Fig. 15. Vista general de los restos del molino de la Marquesa, con el casal sobre la acequia de Mestalla y batán a la izquierda de la imagen en primer plano.

Del casal del molino harinero del s. XIV, afectado por remodelaciones posteriores, se pudo documentar todo el perímetro del edificio, su fachada con puerta en arco ojival y las dos crujías interiores comunicadas también mediante este tipo de arco, así como la sala de las muelas. De ella no se conservaron los espacios de las muelas originales, pero sí las cárcavas y los arcos que las sustentaban (Fig. 16). Su hallazgo puede considerarse como uno de los más espectaculares de esta intervención por su monumentalidad. Se identificaron cinco cárcavas y sus respectivos arcos, todos construidos en sillería, siendo los arcos de medio punto, a excepción del arco norte que era rebajado.

6 Archivo de Protocolos Notariales del Corpus Christi. 2149. Bernat de Montalbà. 6-5-1421 


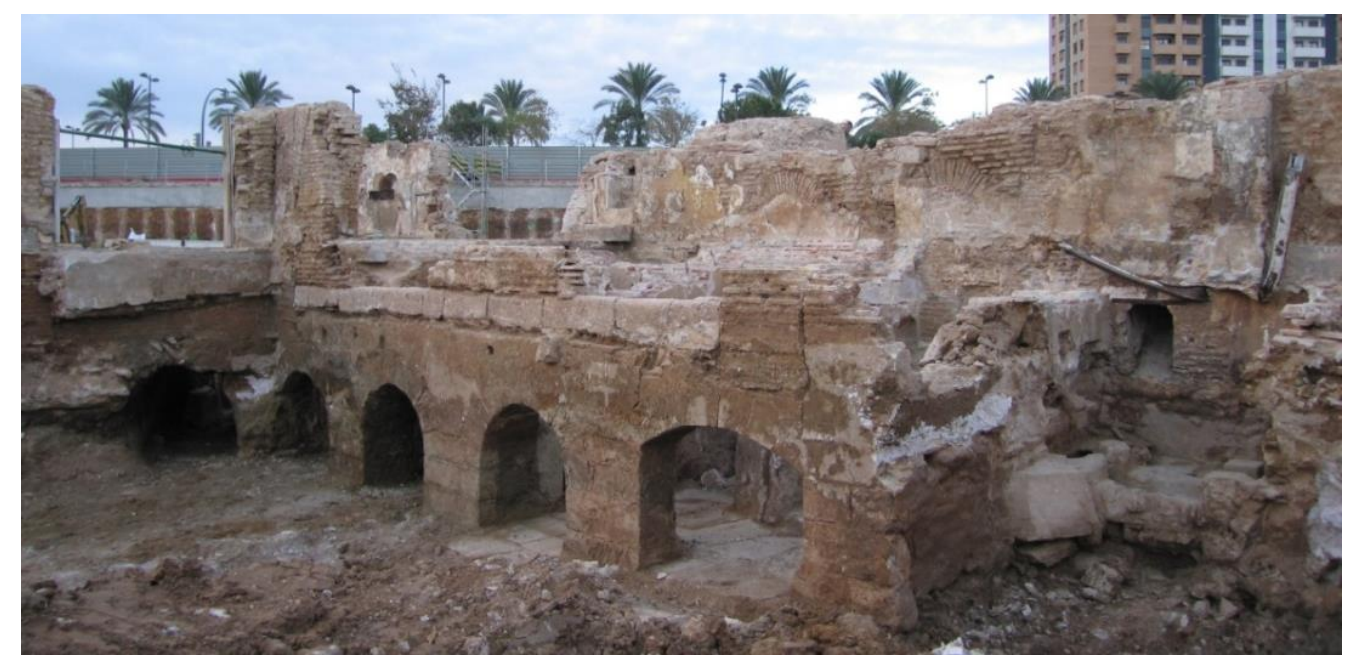

Fig. 16. Arcos de sillería de la salida del agua de las cárcavas. S. XIV.

En el siglo XV se amplió el número de cárcavas con otras dos, que ocupan el espacio del antiguo aliviadero norte y ahora sí se registraron algunos de los espacios para alojar las muelas y sus respectivas harineras. Hacia finales del siglo XV se dotó de un huerto o jardín del tipo hortus conclusus, que presentaba diversos elementos suntuarios, como una fuente pavimentada con azulejos góticos de Manises tipo encadenat y andenes con azulejos del tipo rosa gótica.

En cuanto al molino "draper" o batán, situado al suroeste del casal bajomedieval y de la acequia de Mestalla, su construcción también era de bloques de sillería de piedra calcárea trabados con hormigón de cal. Debía formar un extenso cuerpo que corría a lo largo del margen sur de la acequia, formando una gran "L" respecto al cuerpo de casal situado sobre la acequia. Disponía de dos batanes anexos, cada uno tenía su propia conducción de paredes de sillería y base de losas y fragmentos de muelas reutilizadas, donde giraba una rueda vertical de unos $3 \mathrm{~m}$ de diámetro. Se han registrado las huellas del rozamiento de esta rueda vertical, así como parte de la rampa de acceso del agua que la accionaba. Las ruedas verticales movían sendos ejes horizontales, conocidos como árboles de levas, alojados en unos espacios anexos de planta rectangular con paredes que combinan los bloques de piedra y la sillería. Estos ejes, a su vez, movían los mazos de madera para golpear o abatanar los paños mojados, generalmente lana. Se conservó incluso en un caso el punto de apoyo de estos mazos.

Como se puede apreciar, se trataba de un gran complejo molinero, que se mantuvo hasta finales del siglo XIX tras su transformación en fábrica de harinas por la compañía López y Raga, que en una primera fase siguió accionando la maquinaria con la fuerza del agua mediante la instalación de tres turbinas, que sustituyeron a los viejos rodeznos artesanales.

Las potentes estructuras del molino bajomedieval y moderno implicaron la construcción de muros de delimitación del cajero y tajamares construidos sobre la acequia a la entrada del molino y el aliviadero situado al norte. Sin embargo, en una primera etapa esta edificación no supuso un cambio estructural del cajero de Mestalla, más allá de las obras imprescindibles para conducir y dirigir el agua a las cárcavas.

Centramos la tercera fase de remodelación general de la acequia de Mestalla, tanto en la zona de entrada como en puntos ya alejados del molino, entre la segunda mitad del s. XIV 
y primeras décadas del XV y perdura durante el resto de la época bajomedieval y los siglos XVI y XVII o incluso parte del XVIII. Viene marcada por un relleno sedimentado limoarenoso de coloración gris verdoso con bolsas pequeñas de arena amarillenta de grano muy fino, malacofauna tanto terrestre como acuática, escasa presencia de fragmentos de ladrillos macizos y tejas, algunos cantos y material cerámico (con presencia de lozas azules y doradas, así como de algún fragmento de verde-manganeso y turquesa), todo rodado y con concreciones.

Vista la acequia en un punto lo bastante alejado para no verse influenciada por el molino, el nuevo cajero va a mantener unas dimensiones similares, aunque ligeramente más pequeñas, a las obtenidas en la segunda fase islámica, de $5.10 \mathrm{~m}$, situándose la base de la acequia a la cota de 18.00 m.s.n.m., es decir a $1.80 \mathrm{~m}$ por encima de la base original de los siglos XI-XII. Será a partir de este momento cuando uno de los márgenes del viejo cajero de tierra se refuerza con un muro de mampostería sin mortero.

\subsubsection{Acequia de Petra}

En el apartado de descripción de los cajeros de la Acequia de Petra indicamos que en los dos puntos del extenso solar del futuro Estadio de Fútbol del Valencia C.F donde pudimos excavar esta acequia (extremo oeste junto a la av. Cortes Valencianas y junto a la c/Nicasio Benlloch) la cronología inicial era, invariablemente, de época bajomedieval. En el tramo excavado junto a la calle Nicasio Benlloch fue donde se determinó una secuencia completa, haciéndose posible comprobar que su fundación se ejecutó, sin lugar a dudas, en la etapa de tránsito de finales del siglo XIII a principios del XIV.

Sin que estos datos puedan extrapolarse con total seguridad a toda la acequia principal de Petra, que se divide en las lenguas de Ponça hasta Poble Nou al final de su recorrido, se nos plantea una hipótesis que creemos se debe tener en cuenta ante posibles nuevos hallazgos arqueológicos o documentales.

La interpretación más generalizada es la de considerar todo el sistema de Petra como una creación, sino del mismo origen que Mestalla, sí de al menos de una etapa islámica indeterminada coincidente con todo el sistema general de Mestalla, que simplemente se mantiene, en líneas generales, tras la conquista cristiana de la ciudad en 1238. Sin embargo, retrasar la cronología a la etapa feudal del tramo de Petra que nace de las lenguas situadas antes del poblado de Campanar podría explicar algunas de las irregularidades de los perímetros de riego de Mestalla-Petra-Rambla-Algiròs, como ya habíamos apuntado más arriba: discontinuidad de los tres perímetros de riego de Petra (Campanar, Marxalenes-Goleró y Poble Nou) y autonomía de Rambla y Algiròs (Mangue, 2001; Guinot y Selma, 2005).

La acequia de Mestalla entra en tierras de Campanar tras efectuar un cruce con la Fila de Campanar de Tormos, siguiendo una orientación noreste hasta conectar con el Camí Fondo de Paterna, pero se separa de él efectuando un giro sudeste, situándose en su cauce los molinos Nou o de la Saïdia y de Pobres. Pasado el Molí Nou se localizan las Lenguas de Mestalla-Petra o Rambla-Petra, donde se dividían las aguas de Mestalla, que proporcionaba un tercio de su caudal al Braç de Petra. Desde este punto el Braç de Petra es una acequia pasante en el ámbito de riego de la Fila de Campanar de Tormos. Sigue una dirección sur hasta cruzar el Camino de Paterna a Campanar y alcanzar al Molí dels Frares, movido por sus aguas. Pasado el molino se aproxima a la ribera del río y conecta con la Fila de Campanar y con la acequia de Rascanya en un tramo en el que estos tres grandes canales discurren en paralelo a escasos metros unos de los otros. 
Antes de llegar al Molino del Sol, el Braç de Petra gira hacia el noreste y alcanza el Camino de Paterna a Campanar, dirigiéndose hacia las Lenguas de Ponça o del Roch, que se encuentran en la actualidad tapadas y reformadas, aunque son visibles los cajeros de los dos brazos en que se parte. A la derecha se abre el braç del Mig o de Campanar que atraviesa el núcleo de Campanar, aunque también se le conoce como de Petra. En la actualidad presenta un cajero completamente reformado con paredes de obra de ladrillo hueco y unas dimensiones considerablemente inferiores a las del Braç de Petra que sale a la izquierda. A pocos metros de su nacimiento contaba con una bifurcación en las lenguas que daban paso al rollet del Molí del Conde y sobre todo a la Fila del Pouet, que regaba la mitad oriental de esta partida. La Partida del Pouet, en la actualidad completamente perdida y sacrificada, agrupó un núcleo de hábitat peculiar a lo largo del Camino del Pouet, cuyo pasado islámico quedó demostrado en la excavación de la Alquería de Barberá (Algarra, 2002). El brazo principal del Mig, también conocido como Petra, seguía hacia el núcleo de Campanar, atravesaba y mantenía el riego hasta alcanzar la acequia de Rascanya en un punto próximo a Tendetes (otra de las partidas de Campanar), partida ya regada por la acequia madre de Rascanya.

¿Podríamos pensar que este tramo inicial de Petra y su continuación a lo largo del braç del Mig fue el canal de origen islámico, que formaba la primera derivación de Mestalla? No contamos con datos arqueológicos directos que así lo ratifiquen. En las "reducidas" intervenciones que pudimos efectuar en la Partida del Pouet en el año $1999^{7}$ únicamente se intervino en algunos de los edificios de las antiguas alquerías, pero no en el sistema hidráulico (eran otros tiempos y no existía motivación alguna de efectuar un análisis completo del territorio por parte de las distintas administraciones). No obstante, como se ha indicado, en la Alquería de Barberá se hallaron los restos en el subsuelo de un edificio precedente al construido en el siglo XIV y ampliado en el XV (demolido al finalizar la intervención arqueológica). La cronología de los restos hallados fue establecida en la segunda mitad del siglo XII, viniendo de este modo a confirmar la antigüedad que se suponía para este núcleo de hábitat de la Huerta que tradicionalmente ha sido regado en parte con aguas de Petra. Mientras que el Braç del Mig se ha convertido hoy en día en una pequeña acequia sin prácticamente uso, el Braç de Petra, que sale a la izquierda de las lenguas de Ponça, sigue activo, pues en su largo recorrido todavía riega una importante área de huerta en Poble Nou, entre el Camino de Montcada y el de Carpesa, que constituye una de las pocas reservas de huerta a preservar.

Tras las lenguas de Ponça o del Roch, el brazo de Petra sube en una dirección ligeramente noreste hasta el desaparecido molino de Sant Josep o d'Horta. En este tramo se derivaban los brazos del Batlle y del Molí d'Horta, que regaban las tierras al norte de Campanar desde el cementerio, actuando de barrera al desarrollo de la Fila de Campanar (Tormos), cuyas caídas desaguan en Petra. Esta huerta ha desaparecido completamente por su urbanización. El Moli d'Horta constituía un hito de especial importancia en la red hidráulica y en la de comunicaciones entre la extensa área de la Partida de Dalt y Campanar, Benicalap y Paterna. Se situaba en un enclave de gran belleza paisajística en el sentir de muchos vecinos de Campanar, justo en el punto donde se cruzaban la acequia de Mestalla y su brazo de Petra, cuyas aguas movían al molino. Frente al molino se encontraba el "Bullidor", un remanso

\footnotetext{
7 La urbanización del barrio conocido como Nou Campanar supuso la eliminación, sin ningún criterio de integración urbanística, del antiguo territorio del Camí del Pouet. Con esta triste actuación se perdió de manera irremisible un imprescindible patrimonio histórico y natural de la ciudad de Valencia, integrado por alquerías centenarias, acequias, molinos, caminos y parcelas de huerta vivas y en pleno funcionamiento y lo que todavía fue más grave un desplazamiento doloroso de las gentes que allí vivían. El reciente incendio de agosto de 2014 de la Alquería del Rey, una de las pocas alquerías dejadas en pie y a su suerte, es el último de los turbios acontecimientos vividos en esta antigua Partida del Pouet.
} 
de la acequia con abundante vegetación y sobre todo de anguilas, que eran recogidas especialmente cuando se vaciaba la acequia. Se trataba de un casal medieval, oficialmente conocido como de San José y en otros tiempos de Pellicer (siglo XVII). Fue molino harinero con tres muelas y en los últimos tiempos fábrica de "borra" y limpieza de lanas. Nada de él perdura, la urbanización de la zona lo ha fagocitado, hasta tal punto que incluso la construcción hace unos pocos años de un edificio de pisos en parte del solar que ocupaba no fue sometido a estudio arqueológico (aun habiendo sido denunciado este hecho).

Tras situarse en paralelo en la margen derecho de Mestalla, cambiando su dirección norte por la este, el braç de Petra se enfilaba hacia el molino, donde frente a la entrada de las cárcavas se hallaba un acueducto que cruzaba el cajero de la acequia de Mestalla, la cual pasaba por debajo. La acequia de Petra accionaba el molino y volvía a tomar una dirección norte. El molino, en su emplazamiento estratégico, debía favorecer y minimizar el impacto del paso de Petra sobre depresiones tan importantes como fueron la acequia de Mestalla y el Barranc d'En Dolça.

Este entorno es, además, donde Acequia de Mestalla y el Camí Fondo de Paterna se encuentran por primera vez, aunque como opinamos y así lo indicamos más arriba, sería hacia ese punto del cruce de acequias donde derivaría el tramo de camino romano interpretado como primitivo Camí Fondo de Paterna, que acompañaba, como Mestalla, al Barranç d'En Dolça (Fig. 17).

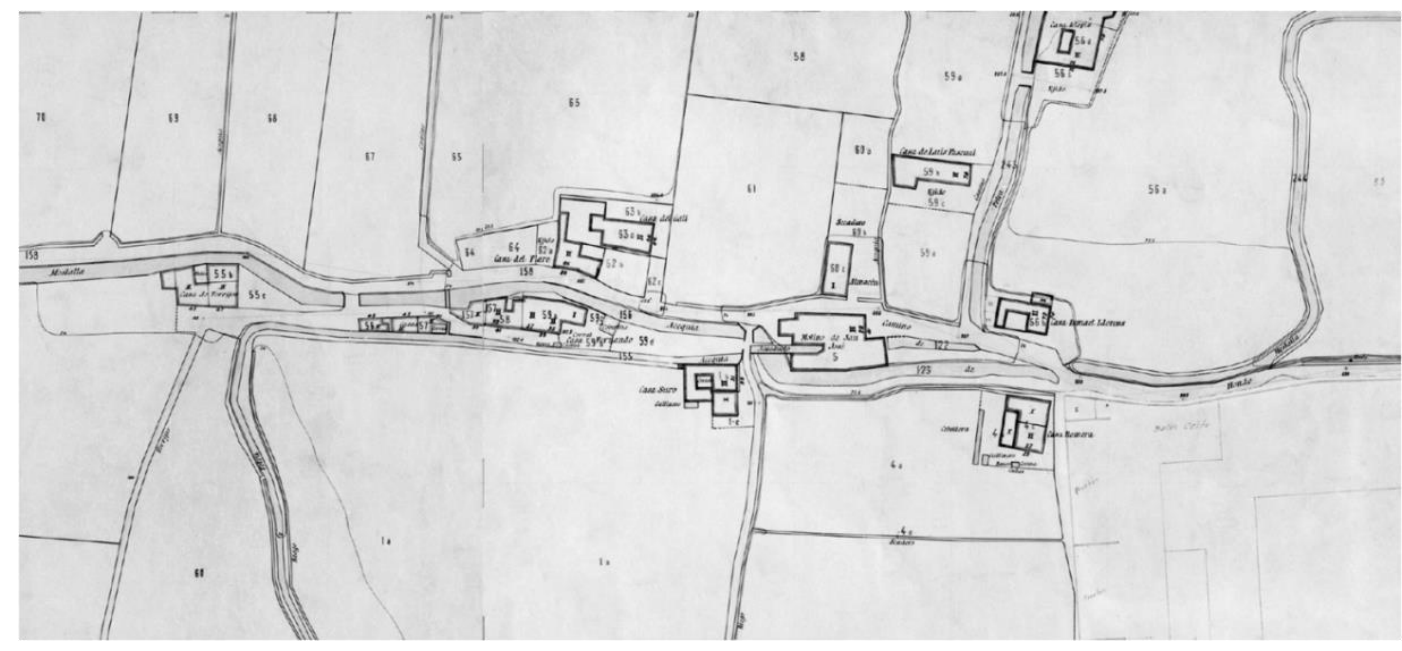

Fig. 17. Entorno del Molino de San José o d’Horta, donde se cruzan las acequias de Mestalla y Petra

Petra sigue a partir de este punto su trazado escalonado hacia el norte, formando una gran "curva" que cierra el paso a los distintos brazos y filas de Tormos, que riegan la práctica totalidad de la partida de Dalt, llegando finalmente al área de la intervención arqueológica. Se trata de un diseño "singular" ideado para el riego de un territorio, el de Poble Nou, alejado y aislado de las otras áreas de riego de Mestalla, incluida la de la "otra" Petra en Campanar. Además, como hemos señalado, desde que comienza su riego tras las lenguas de Ponça corta el desarrollo final de las acequias derivadas de Tormos: la Fila de Campanar y la Acequia del Tragador entre otros canales menores.

Por todo lo expuesto y teniendo presentes las conclusiones derivadas de la excavación arqueológica, proponemos como hipótesis que la construcción del braç de Petra pudo ser motivada por una empresa feudal de puesta en regadío o de mejora del mismo de un sector 
de huerta tal vez con dificultades al acceso del agua (¿incapacidad técnica o saturación de suministro por parte de Tormos, canal que de forma natural podría haber sido el que aportase el riego?), que se ubicaría lejos del punto de partición de aguas de Mestalla, entre Torrefiel, Poble Nou y el Camí de Montcada.

El diseño de la "nueva" Petra pudo suponer una barrera al norte de Campanar para los canales de Tormos del área comprendida entre el molino de la Marquesa al norte, el de l'Horta al oeste y el Camí de Campanar a Paterna al sur. Ante esta circunstancia pudo ser más sencillo dotar de la función de riego a Petra en este punto, que acometer la construcción de estructuras de transporte y paso del agua entre acequias (acueductos).

¿Es posible hallar evidencias de este supuesto en el registro arqueológico? Consideramos que en esta línea se han de interpretar una serie de fragmentos de un canal secundario, que se registraron al este del molino y entre la acequia de Petra al norte y la de Mestalla al sur. Entre las distintas evidencias hemos reconstruido un posible roll (UE. 2020), que se derivaría de Petra a la altura de la actual calle La Safor y que llevaría una orientación norte-sur, cruzando el Camí del Molí de la Marquesa (donde se documentó un tramo de acequia de $1.70 \mathrm{~m}$ de ancho superior) y que desaguaba en Mestalla. Es en este punto donde se pudo analizar toda la secuencia de sus cajeros, que se datan entre la época bajomedieval y el siglo XVII.

En su inicio se trataba de un canal que cortaba distintos niveles de inundación, el superior datado en época bajomedieval, conformando una sección en cubeta, fuertemente encajada, con las paredes rectas y la base plana, con un ancho superior de $2.74 \mathrm{~m}$ y $1.70 \mathrm{~m}$ de altura. No se excavaron nuevos cajeros en ella, sin embargo, se depositaron a lo largo del tiempo hasta tres capas de sedimentos, cuyas superficies fijan las nuevas fases (Fig. 18). Por ello se asiste a una gradual reducción del cauce. El primer relleno de la acequia marca un momento de transición entre los siglos XV y XVI, por lo que podemos suponer un origen también bajomedieval y, según nuestra línea argumental, coetánea a la acequia de Petra, de la que suponemos derivaba para regar el espacio comprendido entre el molino y el camino Viejo de Llíria.

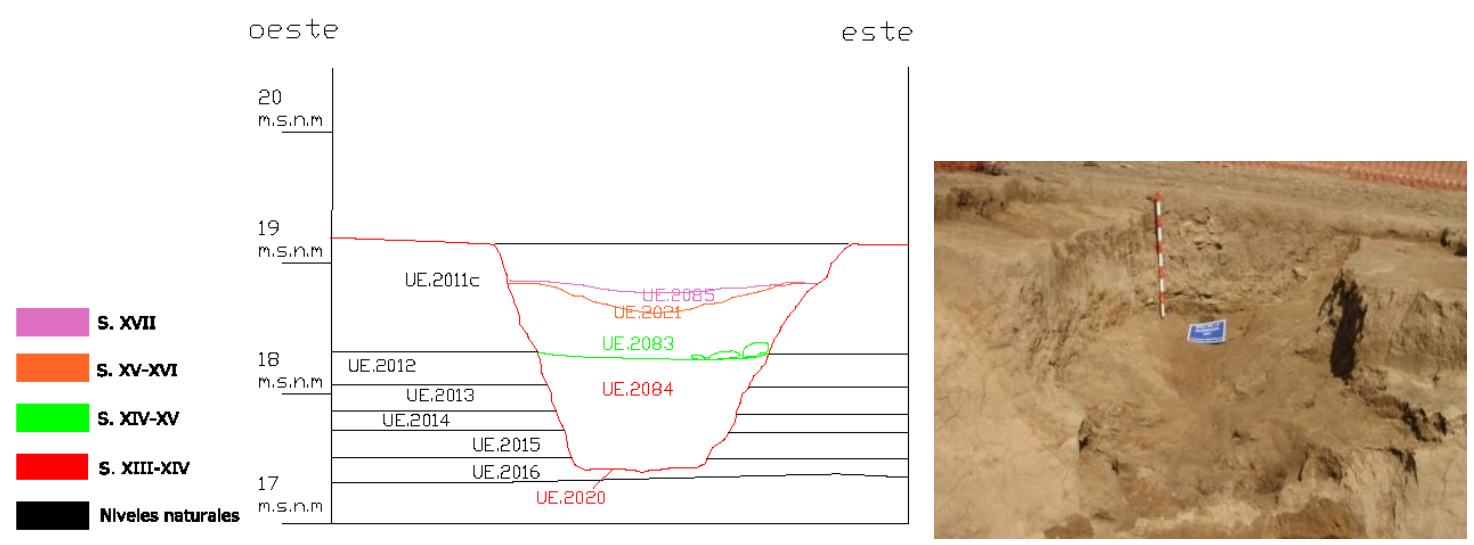

Fig. 18. Acequia secundaria UE. 2020. Sección e imagen al final de su excavación.

La excavación arqueológica aplicada a los cajeros de acequias puede aportar, como esperamos haber demostrado, un volumen de información imprescindible para el estudio de los sistemas hidráulicos, combinada con la aportada desde otras aproximaciones históricas, como son la documental o la lectura del paisaje. En nuestro caso, pudimos asistir a una compleja situación de distintos elementos del paisaje, que se interrelacionaron a lo largo de 
veintidós siglos, sometiéndose a todas las leyes de la estratificación, y que nos brindaron una visión diacrónica de más difícil observación desde otras fuentes históricas.

\section{Referencias}

Algarra Pardo, V.M. (2002): Les primeres arquitectures de l'alqueria en época cristiana. En Del Rey, M. Alqueries. Paisatge i arquitectura en l'Horta. Valencia.

Guinot, E. y Selma, S. (2005): Les séquies de l'Horta nord de València: Mestalla, Rascanya $i$ Tormos. Generalitat Valenciana, Valencia.

Mangue, I. (2001): Marxalenes, de alquería islámica a barrio de la ciudad de Valencia, Ajuntament de València. 